\title{
LA CURVA DE PHILLIPS DE PENDIENTE POSITIVA Y LA CRISIS DE 2008
}

\author{
ADRIÁN RAVIER*
}

\begin{abstract}
Resumen: El paradigma dominante está en crisis. Tanto en la revolución keynesiana (que surge como respuesta a la crisis del enfoque clásico), como en la contrarrevolución neoclásica (que emerge como resultante de la crisis del keynesianismo), han habido aportes significativos en el estudio de la Curva de Phillips. Aquí proponemos un enfoque alternativo al neoclásico, basado en la tradición de la Escuela Austriaca - y en particular en los escritos de Friedrich A. Hayek- La relevancia del estudio se observa en la utilidad para comprender los acontecimientos de la crisis actual. Sólo una Curva de Phillips de pendiente positiva puede explicar esta destrucción masiva de empleo en todo el mundo.
\end{abstract}

Palabras clave: Curva de Phillips, inflación, desempleo, ciclos económicos, crisis de 2008.

Clasificación JEL: B25; E24; E32; E58; N12.

Abstract: Mainstream economics is in crisis. Both in the Keynesian revolution (which emerged in response to the crisis in the Classical approach) and in the neoclassical counterrevolution (spurred from failures of Keynesianism), there have been significant contributions to the study of the relationships known as the Phillips curve. This paper advances an Austrian approach, rooted particularly in the writings of Friedrich Hayek, to the study of the Phillips curve. The relative superiority of the Austrian approach to account for the

* El autor es Doctor en economía aplicada por la Universidad Rey Juan Carlos de Madrid y miembro del departamento de investigaciones de la Fundación Friedrich A. von Hayek. Correo electrónico: a_ravier@hayek.org.ar / adrianravier@yahoo.com.ar Este trabajo fue presentado y discutido en la reunión anual de la Asociación Argentina de Economía Política (AAEP), que tuvo lugar en Mendoza, los días 18, 19 y 20 de noviembre de 2009. Se agradecen los comentarios de Ricardo Crespo, Daniel Heyman y Roberto Dania a las versiones preliminares de este trabajo. La responsabilidad por el trabajo final es exclusivamente del autor.

Procesos de Mercado: Revista Europea de Economía Política Vol. VII, n. $\stackrel{-}{1}$, Primavera 2010, pp. 71 a 121 
current crisis, within the study of the Phillips curve, is analyzed. Only a positive slope of a Phillips Curve can explain this massive destruction of employment all over the world.

Key words: Phillips curve, inflation, unemployment, business cycles, crisis of 2008.

JEL Classification: B25; E24; E32; E58; N12.

\section{I \\ INTRODUCCIÓN}

Ante la crisis global actual varios economistas destacados, como Axel Leijonhufvud (2008a), John Taylor (2008) y Paul Krugman (2009) han señalado la debilidad de la macroeconomía moderna para explicar lo que ocurre y proponer políticas económicas alternativas. Leijonhufvud (2008a; p. 1) tiene la particularidad adicional de afirmar que la Escuela Austriaca tiene más para ofrecer en la comprensión de la crisis actual que el propio keynesianismo, pensamiento este último que él mismo ha defendido durante décadas. ${ }^{1}$

El objetivo general que perseguimos con este artículo es ofrecer una síntesis de la macroeconomía del capital, la que se construye sobre la base de los escritos de la tradición austriaca - resumida en los escritos de Ludwig von Mises (1912), Friedrich A. Hayek (1931 y 1933) y Roger W. Garrison (2001)_, y la que se presenta como alternativa al pensamiento dominante.

El objetivo particular es presentar una Curva de Phillips alternativa a la keynesiana, a la monetarista y a aquella de la Escuela de expectativas racionales, presentando lo que podemos denominar como una Curva de Phillips Austriaca, de pendiente positiva, que tiene importantes implicaciones en los estudios de la neutralidad del dinero, en las expectativas y en los ciclos económicos.

\footnotetext{
${ }^{1}$ Después de ofrecer una síntesis de su comprensión de la crisis actual Leijonhufvud (2008a) sostiene: «This, of course, does not make a Keynesian story. It is rather a variation on the Austrian overinvestment theme.»
} 
En la parte I resumimos el debate de la Curva de Phillips keynesiana (corto plazo) y monetarista (largo plazo), además de presentar la observación empírica de Milton Friedman (1976) a favor de una Curva de Phillips de pendiente positiva. En la parte II ensayamos una respuesta teórica a la observación de Friedman, formulando esta nueva Curva de Phillips. ${ }^{2}$ En la parte III nos apoyamos en la Crisis de 2008 para ilustrar la relevancia de la teoría.

\section{II}

\section{PARTE I: EL DEBATE SOBRE LA CURVA DE PHILLIPS}

El trabajo empírico de Alban William Housego Phillips (1958) ha dado nacimiento a uno de los debates más importantes de la macroeconomía moderna. La Curva de Phillips keynesiana, de pendiente negativa, que observamos en el gráfico I del anexo I, se presenta en la literatura como un trade off de suma importancia para los hacedores de políticas públicas (o policymakers). Los policymakers podrían elegir entre un bajo nivel de desempleo, como $\mathrm{U}_{\mathrm{L}}$, siempre que aceptaran un nivel de precios creciente $\mathrm{o}$ mayor. Alternativamente, si la inflación resulta ser un problema, entonces podrían disminuir su aceleración, y hasta llevarla a un proceso deflacionario. En ese caso, deberán aceptar un nivel de desempleo mayor: $\mathrm{U}_{0}$ para inflación cero, $\mathrm{U}_{\mathrm{H}}$ para la deflación.

Al trabajo de Phillips (1958) se agregaron más tarde las contribuciones de Paul Samuelson y Robert Solow (1960), quienes ofrecieron un estudio similar para el caso de la economía norteamericana, llegando a conclusiones similares.

El trabajo de Phillips (1958) resumía de este modo el enfoque keynesiano, considerando central el efecto animador y estabilizador de la política monetaria anticíclica y destacando su efecto no neutral a corto plazo.

Tres fueron los sucesos que se impusieron ante la hipótesis de Phillips y su trade off. El primero fue representado por la reacción

${ }^{2}$ El fundamento de esta Curva de Phillips de pendiente positiva fue presentado extensamente en mi tesis del programa de doctorado en economía aplicada de la Universidad Rey Juan Carlos de Madrid y compilada en Adrián Ravier (2009). 
teórica general contra el sistema keynesiano, tanto por parte de los monetaristas encabezados por Milton Friedman, como por parte de los economistas austriacos encabezados por Friedrich A. Hayek. El segundo fue que el modelo, si bien se adaptó correctamente para el estudio de Samuelson-Solow (1960), falló en su aplicación a otras economías. Y tercero, el surgimiento del proceso de «estanflación», entendido como un fenómeno de alta inflación y alto desempleo simultáneamente que, como correctamente señala Milton Friedman (1975; p. 89), «volvió algo ridículos los confiados comentarios de muchos economistas sobre "trade off" de inflación por desempleo, basados en curvas Phillips empíricas hechas a medida.»

\section{La Curva de Phillips vertical ajustada por expectativas}

Se produjo entonces lo que Milton Friedman (1976) denominó como la contrarrevolución monetarista, la que relegó el estudio keynesiano sólo al corto plazo y replanteó una nueva Curva de Phillips, ahora de pendiente vertical, dando lugar a un nuevo programa de investigación. ${ }^{3}$ Este programa alternativo, con un particular énfasis en modelos agregados y en equilibrio, incluía la teoría cuantitativa del dinero como eje y otorgaba mayor relevancia a la distinción entre el efecto de la política monetaria en el corto y el largo plazo, prestando atención al rezago (lag) de la política monetaria y a la neutralidad del dinero en el largo

3 Axel Leijonhufvud (2000, p. 515) en un artículo donde se cuestiona qué han hecho los modernos con Keynes replantea la historia de la Curva de Phillips señalando que «la economía keynesiana floreció durante unos veinticinco años sin que hubiera curvas de Phillips. Este fue un agregado tardío. Por otra parte, el propio Phillips no creía que las regularidades que había descubierto en los datos se mantuvieran en condiciones inflacionarias. La econometría de las curvas de Phillips fue vacilante desde el principio y la "curva" nunca tuvo un fundamento teórico comprensible. Por todo esto, son muchos los que dejaron de creer esa construcción aún antes de la revolución de las expectativas racionales (ver, por ejemplo, Leijonhufvud, 1968).» En el mismo sentido argumenta Gerald O'Driscoll (2009; p. 173), quien prefiere hablar de una contrarrevolución de la «macroeconomía neoclásica», que «evolucionó en una síntesis de keynesianismo y monetarismo (no necesariamente representada por Keynes y Friedman).» 
plazo y creando tres nuevas teorías o conceptos: la de las expectativas adaptativas, la tasa natural de desempleo y la teoría aceleracionista de la inflación.

La Curva de Phillips vertical monetarista se expone en el gráfico II del anexo I. Partiendo del punto E, supongamos que la economía representada en el mismo nunca ha registrado un proceso inflacionario. Bajo estas condiciones, y asumiendo un proceso de formación de expectativas adaptativas, lo más razonable es pensar que la tasa de inflación esperada por los agentes para el período 1 será igual a cero.

La curva correspondiente a esa tasa de inflación esperada determinará entonces un nivel de desempleo tal como $\mathrm{U}_{\mathrm{N}}$ (tasa natural). Ahora bien, si los policymakers resolvieran disminuir el nivel de desempleo de la economía, digamos por ejemplo a $U_{L^{\prime}}$ mediante una política monetaria expansiva, se generaría un aumento de precios a una tasa $\mathrm{A}=1 / \mathrm{P} \mathrm{dp} / \mathrm{dt}$ (punto $\mathrm{F}$ ).

Sin embargo, Friedman (1976) demuestra que esto es insostenible. Transcurrido cierto tiempo, los agentes económicos modificarán sus expectativas de precios, guiados por la inflación observada. En otras palabras, los agentes económicos bajo el supuesto de expectativas adaptativas esperarán que los policymakers repitan la política inflacionaria, es decir $1 / \mathrm{Pdp} / \mathrm{dt}=(1 / \mathrm{P}$ $\mathrm{dp} / \mathrm{dt})^{*}$ y quedará definida una nueva curva de Phillips en la cual el desempleo tenderá a aumentar hasta el nivel de la tasa $\mathrm{U}_{\mathrm{N}}$ (punto $\mathrm{G}$ ).

En otras palabras, Friedman (1976) concluye que si los policymakers persisten en su intento por mantener el desempleo por debajo de la tasa natural $\left(\mathrm{U}_{\mathrm{N}}\right)$ deberán acelerar nuevamente el proceso inflacionario y pasar a un nivel de inflación mayor (punto $\mathrm{H}$ ), efecto que poco después se verá neutralizado por la presión de los asalariados por no perder el poder adquisitivo de sus remuneraciones, volviendo entonces nuevamente al desempleo natural (punto I).

La pretensión de mantener una tasa de desempleo menor que $\mathrm{U}_{\mathrm{N}}$ sólo puede sostenerse sometiendo a la economía a un proceso inflacionario de tasa creciente, para mantener la tasa de inflación permanentemente por encima de la que la información pasada le permite anticipar a los agentes. 
Al razonamiento anterior el mismo Friedman lo denominó «la hipótesis aceleracionista de la inflación» (hipótesis que también defendió Hayek en 1958). Esta forma de enfocar el problema llevó rápidamente a la conclusión de que el nivel de empleo era una función de la inflación no anticipada por los agentes, o más rigurosamente: la diferencia entre la tasa de desempleo corriente y la tasa natural de desempleo es una función de la «tasa de inflación no anticipada.»

Los economistas de Chicago concluyeron entonces que la Curva de Phillips keynesiana podrá ser efectiva en el corto plazo, mientras la tasa de inflación no sea anticipada por los agentes económicos. Pero una vez que esto se repita, la política monetaria expansiva tenderá a ser anulada por las expectativas adaptativas, llevando a la curva hacia una pendiente vertical, o más precisamente al nivel de la tasa natural de desempleo.

La continuidad lógica del razonamiento sigue con la afirmación de que, a largo plazo, los agentes anticiparán correctamente la tasa de inflación, a menos que se los «sorprenda» permanentemente generando una inflación acelerada, es decir que la tasa esperada de inflación convergerá a los valores observados $(1 / \mathrm{P}$ $\mathrm{dp} / \mathrm{dt})^{*}=(1 / \mathrm{P} \mathrm{dp} / \mathrm{dt})$, y la relación de Phillips se transformará en una recta vertical al nivel de la tasa natural de desempleo $\left(\mathrm{U}_{\mathrm{N}}\right)$.

Resulta fácil advertir cuál fue la consecuencia de este análisis para la política económica. La conclusión evidente era que toda política monetaria activa que intente reducir en forma permanente el desempleo está condenada en el largo plazo al fracaso porque, o bien lanzará a la economía por una senda de inflación desenfrenada o no conseguirá reducir el desempleo por debajo de su «nivel natural».

La concepción monetarista de la Curva de Phillips fue luego rechazada y a la vez reforzada por la Nueva Macroeconomía Clásica, representada por Robert Lucas de la Universidad de Chicago y Thomas Sargent del Instituto Hoover, quienes modificarían el concepto de expectativas adaptativas por el de expectativas racionales, al mismo tiempo que adoptarían la neutralidad del dinero como un supuesto clave. 


\section{La Curva de Phillips vertical y las expectativas racionales}

Lucas y Sargent presentaron dos objeciones al enfoque monetarista expuesto arriba. Por un lado, dudaban de la relevancia de un mecanismo de ajuste de salarios, por no encontrar un fundamento sólido para la lentitud del ajuste. Desde su punto de vista, los salarios se fijan al nivel que, excluyendo desarrollos inesperados, mantendría siempre al mercado laboral en equilibrio.

Por otro lado, criticaban el supuesto de expectativas adaptativas por ser mecánico y arbitrario. Afirmaban que los trabajadores y las empresas encuentran que resulta en su propio interés buscar los medios más exactos para pronosticar la inflación futura. Los errores de las expectativas de inflación llevan, después de todo, a altos costes, como son un alto desempleo y caídas en las ganancias de las empresas.

Específicamente, la posición de Lucas y Sargent era que los agentes económicos (trabajadores y empleadores) se comportan como si conocieran el «verdadero» modelo de la economía y basaran sus pronósticos de la inflación en dicho modelo, y no en un proceso mecánico como el de las expectativas adaptativas.

Se bautizó este enfoque como expectativas racionales, dado que sería racional que los agentes económicos formaran sus expectativas en base a su «modelo» - o comprensión generalde la economía. En pocas palabras, bajo este modelo los agentes económicos actúan como si contaran con toda la información relevante, lo que les permitirá no cometer errores sistemáticos.

John Muth (1961; p. 24), quien dio nacimiento a esta concepción de las expectativas, afirmaba que «debemos suponer que la gente forma sus expectativas sobre la base de una teoría económica correcta; no que aciertan en cada caso individual, sino que en cualquier período prolongado, en promedio acertarán. En ocasiones particulares, esto llevará a la formación de expectativas sobre la base de expectativas adaptativas, pero de ningún modo será siempre así.»

El mismo Friedman (1975; p. 96) afirma que las personas «no son imbéciles». No van a persistir en el error. Y más en general, no van a basar sus expectativas exclusivamente en la historia 
pasada de los precios. Y se pregunta: «¿Hay alguien en esta sala cuyas expectativas sobre la inflación para el año que viene sean independientes de los resultados de las próximas elecciones británicas? Eso no aparece en los registros de precios del pasado. ¿Serán independientes de las políticas anunciadas por los partidos que lleguen al poder?»

Así podríamos sintetizar en pocas palabras la proposición básica de este nuevo enfoque: el valor futuro que los agentes económicos esperan que asuma una variable determinada es exactamente el mismo que predice la teoría económica relevante para dicha variable.

Podemos así hacer una clara distinción entre las expectativas adaptativas de Friedman y las expectativas racionales de Lucas y Sargent. Mientras que en el primer caso las expectativas se forman bajo la historia pasada, es decir «miran hacia atrás», las segundas se forman en base a lo esperado, es decir que «miran hacia delante».

Como se observó anteriormente, los monetaristas aceptan el efecto no neutral de la política monetaria, el mismo que los keynesianos defienden para el corto plazo. Sin embargo, en el largo plazo, tal efecto se revierte. Las implicaciones de estos nuevos estudios llevaron a los economistas a observar que, bajo el supuesto de expectativas racionales, ahora el efecto de corto plazo también se neutraliza. En la Nueva Macroeconomía Clásica no sólo se acepta la neutralidad del dinero a largo plazo de los monetaristas, sino que además la extienden hasta el corto plazo. La racionalidad fuerte de las expectativas de los agentes, les permite a éstos anticiparse a la política monetaria de la autoridad monetaria, anulando todo efecto real en la actividad económica y el empleo. En este nuevo enfoque, el supuesto de neutralidad del dinero es entonces más fuerte que el de los monetaristas.

Así, la historia de pensamiento macroeconómico nos formula la Curva de Phillips de la escuela de las expectativas racionales, expuesta en el gráfico III del anexo I, donde el efecto de corto plazo de la Curva de Phillips monetarista desaparece, pero nos quedamos con la verticalidad de la misma. Si el policymaker aplica políticas monetarias expansivas, no logrará alcanzar 
efectos reales a corto plazo sobre la actividad económica y el empleo, y condenará a la economía a una mayor inflación.

\section{Milton Friedman y la Curva de Phillips de pendiente positiva}

Así como en los años sesenta la evidencia empírica demostró la carencia de sustento teórico de la Curva de Phillips keynesiana dando lugar a la contrarrevolución monetarista, desde los años setenta y hasta la actualidad la misma evidencia empírica vuelve, pero esta vez para contraponerse a la Curva de Phillips vertical monetarista $-\mathrm{y}$ también a aquella sustentada en las expectativas racionales-.

En el mismo artículo donde Friedman (1976) ofrece la síntesis del debate, plantea que «en los últimos años una inflación más alta a menudo ha sido acompañada por mayor y no menor desempleo, especialmente si se toman períodos de varios años de duración. Una curva de Phillips estadística simple para tales períodos parece de pendiente positiva, no vertical.»

Denominaremos a este dilema, «la observación de Friedman», entendida como aquella en la que Friedman observa una realidad empírica diferente a la ya señalada Curva de Phillips vertical. Observa Friedman que la inflación genera mayor desempleo, sin embargo su modelo basado en expectativas adaptativas o racionales, sumado al supuesto de neutralidad del dinero en el largo plazo, sólo le permite formular una Curva de Phillips vertical. Observa Friedman, sin embargo, una curva de Phillips de pendiente positiva en la que el efecto real de largo plazo no sería neutral. ${ }^{4}$

\footnotetext{
${ }^{4}$ En el mismo sentido se destacan los trabajos de Robert Lucas (1973; pp. 326-334) y William A. Niskanen (2002).
} 
III

PARTE II: EL FUNDAMENTO DE LA CURVA DE PHILLIPS DE PENDIENTE POSITIVA

Así como existe una crítica común de los nuevos keynesianos y los austriacos a la síntesis neoclásica, con sus modelos de equilibrio (general o parcial) y conocimiento perfecto o «relevante», también existe un paralelismo en la crítica que los austriacos y los monetaristas han desarrollado sobre el trade off keynesiano y sobre su desconfianza en los mercados libres. En pocas palabras, la filosofía keynesiana de modelos en desequilibrio es similar a la austriaca, pero cuando hablamos de política económica, es el pensamiento de Chicago el que se asemeja al de Viena (O. Schenone y A. Ravier, 2008).

Friedrich A. Hayek escribió en extenso sobre el tema que aquí encaramos, pero no intentó formalizar una Curva de Phillips. Aun así, podemos observar las siguientes palabras de Hayek (1978): «En conclusión puedo decir que la inflación tiene, por supuesto, otros efectos deficientes, mucho más penosos de lo que la mayoría de la gente comprende cuando no ha pasado por ella, pero el más serio y, a la vez, el menos comprensible, es que a la larga inevitablemente produce la desocupación extendida.»

Hayek está haciendo referencia a las conclusiones últimas de la teoría austriaca del ciclo económico que él mismo contribuyó a formular. La Curva de Phillips de pendiente positiva que presentamos en el gráfico IV del anexo I, no es original en su planteamiento teórico, sino en su formulación gráfica. Lo que intentaremos hacer a continuación es emular lo que hizo Friedman con la Escuela de Chicago, pero para el caso de la Escuela Austriaca. ${ }^{5}$ En definitiva, como ha reconocido el mismo Friedman (1975), las ideas centrales de su Curva de Phillips ya habían sido desarrolladas por Irving Fisher en 1926.

Supongamos entonces que partimos del punto $A$, con un nivel bajo de inflación, y con cierto nivel de desempleo representado, digamos, por la tasa natural de desempleo. Dicha tasa natural

5 Véase A. Ravier (2010a). 
tiene implícitos varios componentes, como la legislación laboral, el salario mínimo o el poder de los sindicatos. ${ }^{6}$

Dentro de la tradición de la Escuela Austriaca, la única forma de alcanzar una situación de estabilidad con pleno empleo, de modo sostenible, es renunciando a practicar políticas monetarias, al mismo tiempo que habría que ofrecer plena flexibilidad en el mercado de trabajo, es decir, erradicando toda la legislación laboral, incluyendo los salarios mínimos. Si esto ocurre, la economía se trasladaría desde el punto $A$ al punto $B^{*}$, desarrollando un proceso genuino de formación de capital, que logra aumentar la productividad, y que sería consistente con una leve deflación de precios. Este proceso, desde luego, no se desarrolla de un día para el otro. Sería necesario todo un proceso de ahorro e inversión, lo que implica tiempo.

En términos de la teoría cuantitativa del dinero, $M V=P y$, Hayek (1931) diría que se debe mantener constante $M V$. Ante un incremento en la productividad y una consecuente subida de $y$, $M V$ debe permanecer constante, permitiendo que baje $P$. Esta deflación de precios, conocida en la literatura austriaca como growth deflation, no tiene los efectos perjudiciales que provienen de la etapa última de un ciclo económico, sino que es la consecuencia de un sano crecimiento económico, el que es consistente, a su vez, con aumentos del salario real (Salerno, 2002).

Los gobiernos tienen, sin embargo, un medio para alcanzar el pleno empleo más rápidamente, que es recurrir a la política monetaria. Como se explicó antes sobre la base del modelo keynesiano y monetarista, el gobierno puede pasar desde el punto $A$ al $B$, recurriendo a la política monetaria, alcanzando el pleno empleo, pero sabiendo que se generará un efecto inflacionario.

Friedman (1976) nos enseñó que el efecto sólo sería de corto plazo, y que retornaría a su tasa natural de desempleo, neutralizando el efecto real en el largo plazo. Pero aquí encontramos el punto de conflicto: ¿Permanecerá la economía en la misma tasa

6 Jeffrey Sachs y Felipe Larrain (1994; pp. 492-503) detallan otros componentes de la tasa natural de desempleo. A saber: migración y aspectos demográficos, salarios mínimos, variabilidad sectorial, seguro de desempleo, poder sindical, impuestos laborales e histéresis en el desempleo. 
natural de desempleo, o se modificará después de la etapa de auge en la que se alcanzó el pleno empleo, y el proceso de reajuste posterior? ¿Es el efecto realmente neutral en el largo plazo?

Apoyándonos en la tradición de la Escuela Austriaca se puede comprender que, ceteris paribus, la economía alcanzará un nivel de desempleo mayor que aquel del inicio del ciclo. La explicación es sumamente lógica y sencilla para un economista austriaco, pero abre muchas incógnitas para el programa de investigación dominante.

La Teoría Austriaca del Ciclo Económico, desarrollada por Ludwig von Mises y Friedrich A. Hayek, nos enseña que el efecto en el largo plazo es no neutral sobre la actividad económica, el empleo y los salarios, y que el proceso de auge (boom) y la posterior crisis y depresión (bust), deja como consecuencia, un achicamiento (horizontal y vertical) de la estructura productiva, que en definitiva, es consistente con una caída del salario real de los trabajadores.

Podemos decir que ceteris paribus, es decir, suponiendo que la legislación laboral, y en particular el salario mínimo, permanece en el mismo nivel que al inicio del ciclo, ahora lleva a más trabajadores a percibir salarios que están por debajo de su nivel, y en consecuencia, el desempleo se incrementa.

Lo cierto es que está en la naturaleza del salario mínimo real mantener estable su valor. Empíricamente, ante cada crisis y depresión, los gobiernos no sólo no flexibilizan el mercado laboral, sino que le agregan mayores rigideces, como la conocida doble indemnización o incluso la prohibición por parte de los empleadores de despedir personal. Tales políticas impiden a la economía hacer el reajuste necesario, que para los austriacos implica que muchos trabajadores se desplazan desde sectores más intensivos en capital hacia sectores más cercanos al consumo, más intensivos en mano de obra.

En el gráfico IV que exponemos en el anexo I, es cierto que la economía retorna a su tasa natural, pero debemos destacar que esta tasa de desocupación tiene poco de «natural» ya que lleva implícita toda una serie de rigideces en el mercado laboral, que son ajenas al mercado.

Debemos insistir que para la Escuela Austriaca el efecto no es sólo nominal, sobre los precios, sino que el desempleo aumenta, 
desde el punto $B$ hasta el punto $C$, el que es mayor al punto $A$ inicial. Si el gobierno insiste en aplicar políticas monetarias y crediticias expansivas para evitar la deflación y la crisis mediante planes de estímulos, entonces dará comienzo un nuevo ciclo, que llevará a la economía a acelerar la inflación y a un nivel de desocupación cada vez mayor, alcanzando quizás el punto $D$, en el corto plazo, para luego instalarse en el punto $E$, una vez que se complete el nuevo ajuste.

Llegamos así a dos conclusiones: 1) en el marco del modelo, que la Curva de Phillips debiera ser de pendiente positiva; 2 ) en el marco de la política económica, que el gobierno no debe aumentar la oferta monetaria si lo que está buscando es un proceso genuino y sostenible de crecimiento y desarrollo económico. En definitiva, como nos enseñara Mises (1949), el gobierno siempre alcanza precisamente los resultados contrarios a los que buscaba.

\section{Las tres implicaciones centrales del estudio}

El estudio realizado tiene tres importantes implicaciones a considerar.

\section{a) La no neutralidad del dinero en el corto y largo plazo}

Hemos observado que en el corto plazo, habría cierto consenso entre keynesianos, monetaristas y austriacos sobre el efecto no neutral de la política monetaria sobre la actividad económica y el empleo. Las diferencias sin embargo, aparecen cuando nos concentramos en los efectos de largo plazo.

Para la tradición austriaca, los monetaristas no logran explicar cuál es la misteriosa razón por la cual estos efectos que sí se reconocen en el corto plazo, se revierten en el largo plazo, volviendo la economía al mismo equilibrio que existía antes de que la expansión monetaria haya tenido lugar. ${ }^{7}$

${ }^{7}$ Este argumento lo he presentado en un panel de teoría monetaria en la reunión anual de la Association for Private Enterprise Education (APEE), que tuvo lugar en 
Es cierto que después del proceso de expansión monetaria y crediticia, y del auge económico correctamente descrito por Irving Fisher (1922), se desarrolla un ajuste de mercado que revierte la tendencia a la baja de la tasa de interés, y que las quiebras generalizadas que caracterizan a la fase de la depresión, logran devolver a la economía a un nivel consistente con las realidades económicas subyacentes. Pero, a nuestro juicio, es un error pensar que las realidades económicas subyacentes no habrán sido modificadas después del proceso de auge y depresión. Es un error deducir del análisis de lo que los austriacos conocen como su teoría del ciclo económico, afirmar que la economía retorna al mismo equilibrio que existía antes de la expansión de los medios fiduciarios.

Dicho de otro modo, la teoría austriaca del ciclo económico nos enseña que ante un reducción artificial de la tasas de interés a corto plazo, se induce a los empresarios a incurrir en una mayor cantidad de errores de los que cometen por error de estimación de los mercados. Desde luego, en un mundo de incertidumbre los agentes cometen errores de estimación y de inversión. Pero si a ello se suma que los indicadores sobre los que toman decisiones de inversión están falseados, entonces la magnitud de los errores se incrementa.

Como sostiene Juan Carlos Cachanosky (2002), «cuando los resultados ex post se conozcan mostrando un rendimiento inferior al esperado o quizás negativo el precio de los bonos y acciones en los que invirtieron bajarán y una parte relativamente importante de los créditos que otorgaron se transformarán en incobrables o morosos. Los bancos verán sus activos reducidos, el crédito se contraerá y la tasa de interés subirá.

Así, debido a inversiones erradas se desemboca en un problema de iliquidez que provoca una caída de la producción de una magnitud superior a la que se hubiese producido por errores empresariales puros. La cantidad de errores se ve multiplicada por la reducción artificial de la tasa de interés que hacen los gobiernos.

Guatemala en 2008. La ponencia se tituló «The non-neutrality of money. A Response to Dr. Humphrey.» La misma fue recientemente publicada en Ravier (2010b). 
De esta manera los economistas de la escuela austriaca llegan a la conclusión de que la caída en el stock de oferta monetaria y de la demanda agregada es "consecuencia" de una mala inversión y no la "causa" de la recesión. Fueron las malas inversiones las que provocaron el problema de iliquidez que desemboca en una caída de la demanda agregada y de la oferta monetaria.»

En otras palabras, durante el proceso de expansión tuvieron lugar numerosos proyectos de inversión que utilizaron cuantiosos recursos económicos para ser llevados adelante. Cuando la tasa de interés sube y varios de estos proyectos de inversión deben ser abandonados emergiendo una serie de quiebras en la actividad productiva, debemos reconocer que lo que está ocurriendo es una destrucción parcial del capital acumulado. Muchos de los recursos utilizados, ya no son recuperados y la actividad económica muchas veces retrocede en relación a su capacidad de producción inicial.

Por otro lado, lo que representa el punto central de la perspectiva austriaca, es que incluso si la economía retornara al mismo nivel de producción que existía antes de la expansión monetaria y crediticia, debemos reconocer que la composición de ese «nivel de producción» se habrá visto alterada, y no sólo en el corto plazo, sino también en el largo plazo.

Dicho esto, podemos ahora concentrarnos en los argumentos que presenta el monetarismo para justificar la no neutralidad a corto plazo. Thomas Humphrey (1984) nos ha ofrecido una síntesis de seis prominentes monetaristas para explicar la argumentación de los economistas de Chicago a la no neutralidad del dinero a corto plazo. ${ }^{8}$ Sintetizando, una lectura detallada de su artículo nos lleva a la conclusión de que la única razón por la cual se da cierta no neutralidad sobre la actividad económica y el empleo obedece a «las restricciones contractuales y a las prohibiciones legales», que retrasan el proceso de ajuste y garantizan que siempre tenga lugar un «efecto sorpresa» de la política monetaria sobre la actividad productiva.

8 Thomas Humphrey (1984) hace referencia a los casos de Alexander del Mar (1836-1926), Irving Fisher (1867-1947), Clark Warburton (1896-1979), Milton Friedman (1912-2006), Karl Brunner (1916-1989) y Allan Meltzer (1928- ). 
Sin embargo, los austriacos logran mostrar que incluso con plena flexibilidad en los contratos, los efectos de la política monetaria tampoco serían neutrales. Y no es posible neutralizar los efectos, en parte porque los agentes económicos no poseen el conocimiento necesario para anticipar en detalle los efectos secuenciales correctamente advertidos por Warburton, y que provocan la política monetaria. No es posible, en otras palabras, evitar el «efecto sorpresa» de la política monetaria.

\section{b) Las expectativas subjetivas}

Del mencionado estudio de la no neutralidad del dinero y de la hipótesis de la tasa natural de desempleo, se desprende la necesidad de profundizar sobre el proceso de formación de expectativas de los agentes económicos.

En contraste con este argumento se ha formado la ya mencionada Escuela de las expectativas racionales. Como dijimos, para esta escuela los agentes económicos, si bien no poseen conocimiento perfecto, sí poseen la «información relevante» que les permite evitar cometer «errores sistemáticos».

Estas investigaciones han generado una nueva reacción por parte de la tradición austriaca, señalando que esta nueva concepción también es falaz. No sólo es falaz suponer que los agentes económicos cuentan con toda la «información relevante» para tomar decisiones y anticiparse a los efectos de la política monetaria, sino que incluso en el caso en que esto fuera así, estos efectos tampoco serían neutrales. Gerald O'Driscoll y Mario Rizzo (1985; p. 222), argumentan que "aunque los empresarios entiendan la teoría a un nivel abstracto o macro, no pueden predecir los aspectos concretos y exactos del próximo ciclo de expansión y contracción. Es decir, no saben de qué manera los aspectos únicos de un episodio cíclico diferirán de los del último episodio, o del ciclo normal. Carecen de la habilidad de hacer micropredicciones, aunque sean capaces de predecir la secuencia general de los eventos que van a suceder. Estos empresarios no tienen razón alguna para renunciar a los beneficios temporales que pueden obtenerse de un episodio inflacionario.» 
Sintetizando, la tradición austriaca muestra por un lado, que si bien existe una coincidencia entre el enfoque austriaco y el monetarista en relación a la no neutralidad del dinero en el corto plazo, esta similitud obedece más a la casualidad que a la causalidad; y por otro, que la formación de expectativas adaptativas y racionales no son del todo correctas, ofreciendo una noción alternativa, conocida bajo el nombre de "expectativas subjetivas", en la que Shackle (1949), Ludwig Lachmann (1955) y Roger W. Garrison (2001) desarrollaron aportaciones fundamentales. ${ }^{9}$

\section{c) Los ciclos económicos}

El trabajo original de Phillips (1958), además de mostrar una curva de pendiente negativa y estable entre el nivel de los salarios monetarios nominales y el empleo, mostraba los sucesivos ciclos económicos que Gran Bretaña experimentó durante casi un siglo.

Phillips curiosamente, y digo esto justamente por la evidencia por él presentada, no logró comprender que los ciclos económicos observados guardaban especial relación con la política monetaria e inflacionaria provocada por el banco central de aquel país. Se concentró más bien en el resultado econométrico y agregado de su estudio, donde la curva más allá del ir y venir, permanecía siempre estable, dando como resultado una Curva de Phillips clásica, de pendiente negativa.

Es por ello que consideramos relevante de este estudio remarcar la consistencia entre lo que sería el modelo de Roger Garrison (2001), con esta Curva de Phillips de pendiente positiva.

Garrison (2001), sobre la base de la teoría austriaca del ciclo económico de Mises y Hayek, ha logrado desarrollar un enfoque gráfico de la teoría, similar en su dinámica al modelo IS-LM de John Hicks. Esta teoría básicamente nos explica que la inyección de dinero, junto con una reducción artificial de la tasa de interés a corto plazo, da lugar a proyectos de inversión que sin

9 Ricardo Crespo (1998) desarrolló una excelente síntesis de la postura de Shackle y Lachmann sobre las expectativas subjetivas. 
la aludida reducción artificial, no habrían tenido lugar. Estos proyectos de inversión son entendidos en la tradición austriaca como «mala-inversión» (malinvestment). La misma da lugar a un auge, que puede estar representado en burbujas en el mercado de valores, así como en el mercado inmobiliario. En el momento que el banco central observa un incremento de las expectativas inflacionarias, eleva la tasa de interés, suaviza la expansión monetaria y crediticia, y con ello múltiples proyectos de inversión dejan de ser rentables. Al interrumpir estos proyectos de inversión, se producen despidos masivos, quiebras generalizadas, y el desinfle de las burbujas, transformando la etapa de auge, en una crisis y depresión.

A continuación nos apoyamos en esta teoría para explicar la crisis global, y a través de ella, comprender mejor la relevancia de la teoría del ciclo, así como de la Curva de Phillips de pendiente positiva.

IV

PARTE III: LA CRISIS DEL 2008. UNA LECTURA HAYEKIANA

La crisis de 2008 será recordada en el tiempo por su profundidad, por su impacto en la economía global y por su duración. Nunca antes la literatura desarrolló tantos paralelismos con la gran depresión de la década de 1930, como en esta oportunidad.

Pocas discutirán la profundidad y el contagio. Pero, ¿por qué hablamos de la duración? Porque si bien varios analistas están afirmando que en 2010 la crisis quedará en el olvido, hay varios argumentos que nos llevan a señalar que la crisis tendrá una forma de $W$, en el sentido de que la aludida recuperación será sólo de corto plazo, fruto de las políticas económicas que la Reserva Federal y el gobierno americano están llevando adelante, y no de un completo ajuste de mercado, que deje atrás los errores de inversión a los que ya hicimos referencia, y que surgen como consecuencia de la política monetaria y crediticia. ${ }^{10}$

${ }^{10}$ Resulta un interesante ejercicio repasar varias proyecciones equivocadas de importantes analistas durante la gran depresión. John Maynard Keynes por ejemplo, decía 
Nótese que esa crisis en forma de $\mathrm{W}$ es consistente con la dinámica de la Curva de Phillips de pendiente positiva, en el sentido que el gobierno puede evitar un completo ajuste en el corto plazo, pero inevitablemente el ajuste deberá completarse más tarde, llevando a la economía a un desempleo extendido.

\section{La Reserva Federal durante las décadas de 1980 y 1990}

El origen de la crisis de 2008 no debemos buscarlo únicamente en los excesos del gobierno americano o de la Reserva Federal durante el período 2001-2006. Tal ha sido en general, la posición que han adoptado en sus últimos escritos los economistas de la Escuela de Chicago (Anna Schwartz, 2009; Allan Meltzer, 2009).

Si bien la conclusión a la que llegan estos autores es correcta, la misma es sólo parcial. Un completo estudio de la crisis deberá ahondar necesariamente en la política monetaria que la Reserva Federal llevó adelante en las décadas de 1980 y 1990. En tal sentido, podemos tomar los trabajos de Roger W. Garrison (2009a) y Gerald O'Driscoll (2009).

Garrison (2009a; p. 191) identificó a dicho período como aquel en el que la Reserva Federal aplicó una «Learning-by-doing strategy» (estrategia de aprender sobre la marcha).

O'Driscoll (2009; pp. 175-176) por su parte, señala que el «inflation targeting» comenzó en la década de 1980. La Reserva

en 1927 que «no vamos a tener más crisis en nuestra época». O el presidente de Estados Unidos Calvin Coolidge, en un discurso del 4 de diciembre de 1928: «Ningún Congreso de los EE.UU. antes reunido, al analizar el Estado de la Unión, se ha encontrado con un futuro más favorable que el que aparece en este momento. En el ámbito nacional hay tranquilidad y contento, y récord de años continuados de prosperidad. En el ámbito internacional reina la paz y la buena voluntad que derivan de la mutua comprensión.» Y por supuesto, no podemos olvidarnos de Irving Fisher: «Puede que haya una recesión en el precio de las acciones, pero nada que tenga que ver con un crash.» (New York Times, 5 de septiembre de 1929). «El precio de las acciones parece haber alcanzado un nivel alto permanente. No creo que pueda darse próximamente una bajada ni siquiera de 50 ó 60 puntos, como los bajistas han predicho.» (17 de octubre de 1929).

Estos infundados mensajes optimistas no son casuales. Las crisis económicas suelen destruir las expectativas y las señales de mayor confianza son las que permiten acelerar la recuperación. 
Federal de Volcker terminó con el énfasis en la cantidad de dinero en 1982, y se concentró en la evolución de los precios. Greenspan llegó en 1987 y continuó centrándose sobre los precios. La economía americana experimentó una década de fuerte crecimiento económico y dos crisis financieras. La primera, es conocida bajo el nombre «saving and loan meltdown» (S\&P), recordada porque aproximadamente 1300 de 4039 instituciones financieras cayeron en el período 1980-94. La segunda fue una crisis de los bancos comerciales, vinculada a la crisis S\&P, donde 1600 bancos tuvieron problemas, algunos de los cuales fueron rescatados.

O'Driscoll (2009) menciona además dos crisis bursátiles durante el período. El Crack de Wall Street del 19 de octubre de 1987, en el que los inversores perdieron más de 500.000 millones de dólares en sólo un día. Y la burbuja bursátil de las «dotcom» cuyo desenlace se produjo en el año 2000.

O'Driscoll (2009) concluye que el control, primero sobre el dinero, y luego sobre los precios, trajo aparejada una mayor volatilidad, y que el pánico de 2007 es sólo el último de los tsunamis financieros. El patrón burbuja, crash, a veces pánico, reflación y una nueva burbuja - descrito por O'Driscoll- es lo que intentamos mostrar en la elaboración de la Curva de Phillips de pendiente positiva presentada en el gráfico IV del anexo I.

\section{La crisis de 2001}

Entre 2001 y 2002, la burbuja bursátil formada en torno a las compañías tecnológicas se desinfló. Néstor Restribo (2002) sintetizaba los números del espectacular derrumbe: «La angustia de miles de inversores de Estados Unidos, que perdieron fortunas primero por el estallido de una burbuja especulativa y más recientemente por fraudes contables en varias empresas, se puede ilustrar así: si en marzo de 2000, en el pico del casino que fue Wall Street en los 90, el valor total del mercado de acciones era de 17,2 billones de dólares, hoy se derrumbó a 10 billones de dólares. La pérdida, en algo más de dos años, fue de 7 billones de dólares. Es un monto difícil de imaginar, casi equivalente al PIB 
de toda la Unión Europea o al 80 por ciento del PIB del propio EE.UU.»

La lectura de aquel artículo me llevó a escribir un ensayo al que titulé «Estados Unidos en una nueva gran depresión», publicado por la Fundación Atlas para una Sociedad Libre (hoy Atlas 1853), hacia fines de 2002. Allí analicé el desarrollo de las acciones de Wall Street, las dudas que se le planteaban al gobierno de George Bush (h) sobre su idoneidad, el problema de no contar con un presupuesto equilibrado (no sólo a nivel nacional), su creciente déficit comercial, los escándalos contables y la burbuja inmobiliaria, para concluir que aquella crisis fue principalmente el resultado de la política monetaria de Alan Greenspan al frente de la Reserva Federal a lo largo de la década de $1990 .{ }^{11}$

Y es que el titular del Sistema de la Reserva Federal hizo caso omiso de la «Regla de Hayek» aludida más arriba, de permitir una reducción de los precios. En términos de la ecuación cuantitativa, MV=Py, Hayek (1931) proponía, en tiempos de normalidad, mantener constante $M V$, lo que implica que ante aumentos de productividad — como los ocurridos en la década de 1990y su consecuente aumento real del producto $y$, la economía debió evidenciar un proceso leve de deflación de precios, $P$.

Esta política desde luego no era apoyada únicamente por Hayek. En Precios y Producción (1931; pp. 97-98) Hayek sostiene: «El que no haya ningún peligro en que los precios caigan cuando la producción sube ha sido subrayado una y otra vez, por ejemplo, por A. Marshall, N.G. Pierson, W. Lexis, F.Y. Edgeworth, F. W. Taussig, L. Mises, A.C. Pigou, D.H. Robertson y G. Haberler. (Para referencias más detalladas véase mi artículo "The Paradox of Saving", Economica, mayo de 1931, p. 161.) Cf. También

11 Aquel trabajo incluía una síntesis del paralelismo que Milton Friedman (2000) encontraba entre la gran depresión, la crisis de Japón y la crisis que se desencadenaría un año más tarde. Friedman, alertando de la importancia que la política monetaria tendría en los años siguientes, concluía: «El futuro dependerá de cómo se desarrolle la política monetaria. Mientras el actual crecimiento monetario de más de 10 por ciento es sostenible y quizá incluso deseable como defensa de la contracción y en reacción a los hechos del 11 de septiembre, una continuación de tal crecimiento monetario nos aseguraría la reaparición de la inflación. Sin embargo, la Reserva Federal previno la caída y pienso que preverá también al alza.» 
la propuesta de estabilización planteada por el Dr. Maurice Leven, mencionada por W. J. King en el Journal of American Statistical Association, marzo de 1928, suplemento, p. 146, y el artículo de R. G. Hawtrey en el Journal of the Royal Statistical Society, vol. XCIII, Parte I, 1930.»

El hecho de que la Reserva Federal se concentrara sólo en la evolución de los precios, la llevó a aplicar una política de dinero fácil, que no se plasmó en un aumento elevado del nivel general de precios, por el contrapeso que significó el aludido aumento de productividad.

\section{Discrecionalidad versus Reglas monetarias: El período 2001 a 2007}

Ante la recesión de 2001, la Reserva Federal de Alan Greenspan decidió expandir agresivamente la oferta monetaria, medida por M2, en torno a un 10 por ciento por año. La expansión fue acompañada - como muestra el gráfico $\mathrm{V}$ del anexo II- por sucesivos y discrecionales recortes de la tasa de interés, que comenzó el 2001 en un 6.25 por ciento y terminó —el mismo año—en un 1.75 por ciento. La reducción continuó durante los dos años siguientes, alcanzando su pico más bajo a mediados de 2003, en un valor récord del 1 por ciento, donde se mantuvo estable por un año.

La tasa de interés real fue negativa, señalando que la tasa de interés nominal fue más baja que la tasa de inflación por unos dos años y medio, algo que Lawrence White $(2009$, p. 116) ha señalado como «sin precedentes».

¿Podemos juzgar que esta política monetaria de la Fed fue excesiva? Lawrence White (2009, p. 117) afirma que sí, y lo demuestra con tres reglas monetarias.

En primer lugar, la recién aludida «Regla de Hayek», que habría implicado mantener constante la masa monetaria, y permitir que los precios cayeran durante los aumentos de productividad de la década de 1990. Claramente la Fed no siguió estas recomendaciones olvidadas. En segundo lugar, la famosa regla de Friedman, en la que la Fed debió haber aumentado la cantidad de dinero en proporciones bajas y estables. La Fed tampoco 
siguió esta regla. En tercer lugar, la regla de Taylor, cuyo autor se ha ocupado personalmente de mostrar lo alejado que la Fed estuvo de su regla durante el período en cuestión.

Como una prueba cuantitativa de la responsabilidad de la «Greenspan Fed» en la crisis subprime, John Taylor (2008; p. 2) ofrece el gráfico VII, donde se compara la «regla de Taylor» que guía a los bancos centrales de Estados Unidos y la Unión Europea en la fijación de la tasa de interés a corto plazo, versus la tasa de interés efectivamente fijada por la Fed en el período 2000 a 2007. Bajo dicha evidencia, Taylor muestra la política de dinero fácil entre 2002 y mediados de 2006, cuando la tasa observada fue menor que la sugerida por su famosa regla. ${ }^{12}$

\section{El mito del «saving glut»}

Sería injusto, sin embargo, no aludir aquí a la defensa que Alan Greenspan (2005; 2007; 2008a; 2008b; 2008c) y Ben Bernanke (2005; $2006 ; 2007 ; 2009)$ han desarrollado como respuesta a estas acusaciones. Los dos últimos presidentes de la Fed se han manifestado inocentes de la responsabilidad de crear la burbuja de crédito que diera lugar a la burbuja inmobiliaria y a la crisis de 2008. Su defensa, se puede sintetizar en dos puntos: (1) la teoría del «saving glut» según la cual el crédito que dio lugar a la burbuja inmobiliaria no fue originado en la Fed, sino en un fenómeno global, por una «abundancia mundial de ahorros» que redujo «naturalmente» la tasa de interés; (2) la base monetaria y M2 no crecieron demasiado rápido.

12 Aun cuando la regla de Taylor nos permite observar los excesos de la Fed en el mencionado período, la misma no ha estado exenta de críticas por parte de la literatura austriaca. Roger W. Garrison (2009a, pp. 192-193) afirma que la regla de Taylor es una regla de tasas de interés sólo en el nombre. La ecuación en la que se basa fue introducida por Taylor en 1993, como una descripción de la política de la Fed. «Significantly, Taylor introduced his equation not as a prescription for setting Fed policy but rather as a description of the Fed's past policy moves. [...] In short, the Taylor Rule becomes the baseline for a learning-by-doing strategy. With enough confidence on the part of the Federal Reserve that its past decisions qualify collectively as a "good performance", the Taylor Rule becomes a ready formula for it to keep doing what it has been doing.» 
Y es que hay algo de verdad en el primero de estos dos puntos. Como observamos en el gráfico VI del anexo II la tasa de interés nominal de largo plazo, a 30 años, relacionada con las hipotecas en Estados Unidos, efectivamente cayó 113 puntos básicos entre 2001 y 2004, mientras que la inflación cayó sólo 15 puntos básicos. Sin embargo, como señalamos arriba la Fed redujo aún más su tasa de interés a corto plazo, en 525 puntos básicos, indicando una política de dinero fácil. M2 creció, como notamos arriba, a una tasa inusualmente alta por lo menos por dos años. Lawrence White (2009, p. 118) concluye que «el reclamo de Greenspan de que el crecimiento de la oferta monetaria fue lento, no puede ser sostenido.»

Por su parte, Nicolás Cachanosky (2010) ilustra el punto: «Es cierto, como sugería Greenspan, que la Fed opera sobre las Fed Funds, que son tasas a corto plazo, mientras que los créditos hipotecarios se manejan con tasas de largo plazo. Pero no es menos cierto que al disminuir las Fed Funds se generó un traspaso de créditos hipotecarios a tasas fijas (que dependen de las de largo plazo) a créditos hipotecarios con tasas flotantes (que dependen de las tasas de corto plazo de un año); afectando, al fin de cuentas, a los créditos hipotecarios.» La evidencia empírica recolectada por Cachanosky (2010) «muestra la evolución en base 100 de los créditos hipotecarios con tasa fija y de los créditos hipotecarios con tasa flotante (ARM por sus siglas en inglés: Adjusted Rate Mortgage). No hace falta la correlación para ver que ambas series se mueven de manera similar.»

También resulta ilustrativo el comentario de Roger Garrison, quien pone en discusión que un flujo de nuevos ahorros haya generado presión hacia la baja de la tasa (natural) de interés. Bajo este argumento, Garrison (2009a, p. 195) señala que «Greenspan estaba sólo siguiendo la reducción de la tasa de interés de mercado». Pero al entender de Garrison esto sugeriría una alteración de las condiciones de mercado, y la abundancia mundial de ahorros, y su impacto sobre una baja tasa de interés natural, debería prevalecer por cierto tiempo. Esperaríamos que esas tasas de interés y su consecuente crecimiento económico, sean más o menos sostenibles en el tiempo. ¿A qué obedece entonces la subsecuente subida en la tasa de interés? Para Garrison, esta 
subida pone de manifiesto que la reducción no era sostenible, lo que nos invita a mirar otros factores, más específicamente la política de la Fed.

George Reisman (2009) es todavía más profundo. Su trabajo, sobre la base de la teoría austriaca del capital, apunta específicamente a desmentir el «mito del saving glut», señalando cinco argumentos centrales: Primero, si los ahorros fueran responsables de la crisis, debimos haber experimentado una reducción del gasto en consumo en los países en cuestión. No hubo tal evidencia. Segundo, el ahorro implica un crecimiento en la oferta de bienes de capital, más producción, y precios más bajos, incluyendo precios más bajos en bienes de capital e incluso en la tierra. Estos son resultados incompatibles con las burbujas de activos que experimentamos. Tercero, si de algún modo el ahorro fuera responsable de la burbuja inmobiliaria, los recursos financieros no podrían haber desaparecido de un momento a otro. Estos recursos financieros se detuvieron como consecuencia del fin de la política de dinero fácil y la revelación de la falta de capital. Cuarto, si los ahorros abundan, los bancos y las empresas tendrían más capital, no menos. La falta de capital es precisamente el producto de la mala-inversión y el sobre-consumo, que son consecuencia de la política crediticia expansiva, no de un mayor ahorro. Quinto, y especialmente importante, es notar que en los trece años entre 1994 y 2006, la tasa de ahorro de Estados Unidos, incluyendo todos los ahorros externos que entraron al país relacionados con los déficit de cuenta corriente, nunca excedieron el 7 por ciento, y en ocho de esos trece años, fueron sólo del 3 por ciento o menos.

Reisman (2009) concluye que los aludidos «ahorros», entrando a la economía americana vía déficit en cuenta corriente, no representan ahorros, sino el producto de la expansión monetaria y crediticia que la Fed lleva adelante.

Este mismo aspecto fue estudiado por el economista español Juan Ramón Rallo (2009), quien señala que: «El supuesto ahorro asiático no era en realidad ahorro a largo plazo. Los estadounidenses saldaban su déficit exterior vendiéndoles deuda a los asiáticos y los asiáticos (especialmente los chinos) utilizaban esa deuda como respaldo para emitir su propia moneda interna. ¿Consecuencia? El poder adquisitivo se duplicaba: Estados Unidos 
iba siempre defiriendo sus pagos (podía consumir a crédito de manera indefinida) y los asiáticos iban transformando esas promesas de pago futuras en dinero presente. Los datos son inapelables: entre 2002 y 2008 el déficit exterior acumulado de Estados Unidos con China fue de 1,34 billones de dólares, lo que en buena medida fue sufragado por los activos estadounidenses adquiridos por China durante ese período (1,07 billones) y que se corresponde a su vez con los aproximadamente 1,35 billones de renminbis (valorados en dólares) que emitió el Banco Central chino. Lo que sucedió fue, por tanto, que China concedió crédito a largo plazo a Estados Unidos sin esperarse a cobrarlo. Esto poco o nada tiene que ver con un aumento del ahorro, más bien con un cobro anticipado vía inflación.»

\section{La etapa de auge de la teoría austriaca del ciclo económico}

Aceptando entonces la tesis de que la Fed se excedió en su política monetaria, nos concentramos en la teoría austriaca del ciclo económico. La mencionada teoría enseña que la política discrecional de expansión monetaria y crediticia permitió, al menos momentáneamente, abandonar las expectativas recesivas de 2001.

A una política monetaria expansiva le sigue una primera etapa de crecimiento económico y grandes beneficios empresariales. En tal sentido, el efecto real y positivo descrito por los autores keynesianos y monetaristas, sobre la actividad económica y el empleo, sería consistente con el enfoque austriaco, el que se observa en el pasaje de $A$ a $B$, en el gráfico IV del anexo I.

Gracias a estas tasas artificialmente reducidas muchas firmas pudieron emprender proyectos de inversión que, en ausencia de intervención, habrían resultado inviables.

Debido a una «legislación favorable» para el sector inmobiliario, éste concentró la mayor parte de las inversiones. Se formó así lo que conocemos como «burbuja hipotecaria». ${ }^{13}$

13 En un claro ataque a quienes argumentan que la crisis fue el resultado de desregular los mercados financieros Allan Meltzer (2009; p. 27) desafía: «I would challenge 
Lawrence White (2008), Leland Yeager (2009) y Anna J. Schwartz (2009) explican cuáles fueron los cuatro principales excesos del gobierno americano para favorecer al sector:

1) La Federal Housing Administration (FHA), fundada en 1934, aseguraba que los préstamos hipotecarios otorgados por empresas privadas exigían al prestatario ciertas garantías. Para que un cliente calificara, la FHA originalmente requería - además de otros puntos- que el cliente contara con el 20 por ciento del dinero necesario para comprar la propiedad. A parentemente, por razones burocráticas, la FHA redujo los requerimientos. En 2004 el programa más popular de la FHA redujo el requerimiento a sólo 3 por ciento, afrontando en el Congreso solicitudes por reducirla a 0 por ciento. El resultado fue un aumento en la tasa de default en el pago de las hipotecas.

2) La Community Reinvestment Act es una Ley aprobada por el Presidente Jimmy Carter en 1977 y ampliada en 1989 y 1995. Fue creada para prestar dinero a las «clases menos favorecidas», intentando que aquellos que no pueden cumplir con los requisitos bancarios, puedan acceder al crédito y a la compra de viviendas. Si bien en los primeros años no cumplió ninguna función importante, a partir de 1995 los reguladores pudieron negar una fusión a los bancos o incluso abrir nuevas sucursales, en la medida que no cumplieran con las disposiciones allí impuestas. Así, White explica que grupos como la Association of Community Organization for Reform Now (ACORN) presionaron activamente a los bancos para otorgar préstamos bajo la amenaza de registrar quejas, y así disminuir el rating del banco privado. En respuesta a las nuevas reglas del CRA, algunos bancos se asociaron a grupos comunitarios

anybody to point to something important that was deregulated during the last eight years. Nothing much was deregulated. The last major financial deregulation was the 1999 act that President Clinton signed, removing the Glass-Steagall provisions separating comercial and investment banking.» Gerald O'Driscoll (2009; p. 167), por su parte, agrega que no sólo es un mito que la desregulación del capitalismo financiero fue la causa de la crisis, sino además, que junto al sector de la salud, los servicios financieros constituye la industria más regulada de la economía. 
para distribuir millones en hipotecas a clientes de pocos recursos, a los que antes les era imposible acceder al crédito.

3) Mientras tanto, a partir de 1993, los bancos privados comenzaron a recibir acciones legales por parte del Department of Housing and Urban Development (HUD) por rechazar demandas de hipoteca. Para evitar estas presiones y problemas legales, los bancos se vieron obligados a relajar los requisitos de ingresos que solicitaban a los demandantes de hipotecas.

4) El Congreso entonces presionó a Fannie Mae y Freddie Mac para incrementar la compra de hipotecas. Russell Roberts (2008), profesor de economía en la George Mason University, explicó en the Wall Street Journal que «desde 1996, el HUD requirió que el 12 por ciento de todas las compras de hipotecas realizadas por Fannie Mae y Freddie Mac fueran préstamos “especialmente económicos", típico de clientes con ingresos que están por debajo del 60 por ciento promedio. Ese número se incrementó al 20 por ciento en el 2000 y al 22 por ciento en 2005. En 2008 se incrementó a 28 por ciento. Entre 2000 y 2005 Fannie y Freddie cumplieron sus objetivos, financiando cientos de miles de millones de dólares en préstamos muy arriesgados a gente que compró su casa con menos del 10 por ciento del dinero necesario.»

En el corto plazo, Fannie y Freddie encontraron que sus negocios - ahora más flexibles-eran rentables, por lo que continuaron la expansión en la compra de hipotecas.

White $(2008$, p. 6) explica que «la hiperexpansión de Fannie Mae y Freddie Mac fue posible por el respaldo que éstos recibieron del Tesoro de los Estados Unidos.» Para financiar el enorme crecimiento, Fannie Mae y Freddie Mac tuvieron que tomar prestadas enormes sumas en el mercado financiero. Los inversores quisieron prestarle dinero a las dos compañías patrocinadas por el gobierno, con tipos de interés muy bajos para el riesgo que ambas asumían. Cuando ambas empresas colapsaron, y pasaron a ser más conservadoras, el Tesoro explícitamente respaldó las deudas de Fannie y Freddie. ${ }^{14}$

14 Allan H. Meltzer (2009; p. 25) en sus reflexiones sobre la crisis financiera, comienza justamente por plantear el cierre, lo antes posible, de estas dos compañías. «First, 
Así, millones de personas aprovecharon la situación para comprar viviendas. El aumento de la demanda impulsó la construcción residencial (en Estados Unidos, se construyeron más de 4,6 millones de nuevos hogares entre 2003 y 2006) y fuertes alzas de precios de las ya existentes (el incremento alcanzó el 40 por ciento, entre 2002 y 2006).

Volviendo a la evidencia empírica recolectada por John Taylor (2008), el gráfico VIII muestra precisamente el boom de los permisos de construcción (variable correlacionada con el precio de los inmuebles). Se observa que el boom que se verificó entre 2002 y mediados de 2006 habría sido apenas una loma (counterfactual) si la Reserva Federal hubiera seguido la regla sugerida por Taylor.

No podemos dejar de mencionar aquí la aseveración de Alan Greenspan en su libro «La era de las turbulencias» (2008a), donde muestra que el titular de la Reserva Federal, sabía precisamente lo que estaba haciendo: "Yo era consciente de que la relajación de las condiciones de crédito hipotecario para los prestatarios subprime aumentaba el riesgo financiero y de que las iniciativas de propiedad de vivienda subvencionada distorsionan los resultados del mercado. Pero creía, y sigo creyendo, que los beneficios de una ampliación de la propiedad de viviendas compensan el riesgo.» 15

Lo cierto es que, con el tiempo, parte de la expansión crediticia se volcó en otros sectores. La burbuja dejó de ser puramente hipotecaria para convertirse también en bursátil. Entre 2003 y 2006, el Dow Jones creció, sin considerar los dividendos, un 45 por ciento.

we should close down as promptly as possible Fannie Mae and Freddie Mac. There never was a reason for those two institutions, other than to avoid the congressional budget process.» El caso de Fannie Mae y Freddie Mac «is an example of bad government policy.»

15 También hay que destacar que Paul Krugman (2002), en un artículo publicado en The New York Times, aconsejó a Greenspan precisamente reemplazar la burbuja del Nasdaq con la burbuja inmobiliaria, como medio para paliar la crisis de 20012002. En sus propias palabras: "To fight this recession the Fed needs more than a snapback; it needs soaring household spending to offset moribund business investment. And to do that, as Paul McCulley of Pimco put it, Alan Greenspan needs to create a housing bubble to replace the Nasdaq bubble.» 
Como predice la teoría austriaca, en la fase previa a la actual crisis, los extraordinarios beneficios se manifestaron en las grandes alzas de Wall Street y en las ganancias de compañías constructoras como Meritage Homes, Cetex Corporation, Lennar Corporation y DR Horton Inc.

\section{La teoría del auge «insostenible»}

En su Teoría del Dinero y del Crédito, Ludwig von Mises (1912; p. 338) advertía: «llegará un momento en que ya no será posible seguir aumentando la circulación de medios fiduciarios. Entonces, se producirá la catástrofe, con las peores consecuencias, y la reacción contra la tendencia alcista del mercado será tanto más fuerte cuanto más largo haya sido el período durante el cual el tipo de interés de los préstamos estuvo por debajo del tipo natural de interés y cuanto mayor haya sido el alargamiento de los procesos indirectos de producción no justificados por la situación del mercado de capital».

Durante la etapa de expansión, debido a la política de «dinero fácil» de la Fed, numerosos bancos otorgaron créditos a tasas bajas sin analizar correctamente el riesgo crediticio.

Pero en 2004, en un discurso ante el Congreso de los Estados Unidos, Alan Greenspan manifestó la necesidad de elevar la tasa de interés para prevenir los primeros síntomas de inflación y desalentar la toma de nuevas hipotecas para la compra de viviendas. Así, en poco tiempo, la tasa de referencia trepó del uno hasta el 5,25 por ciento.

El gráfico VIII nos muestra precisamente la abrupta caída de los permisos de construcción, que coincide con el incremento de la tasa de interés.

La contracción del crédito no sólo redujo la demanda de propiedades y sus precios, sino que también elevó las cuotas de aquellos que habían comprado sus viviendas a tasa variable.

Los bancos comenzaron a experimentar grandes aumentos en la morosidad y los efectos se extendieron al mercado bursátil, manifestándose, desde principios de 2007, en las caídas en las bolsas de todo el mundo. 
Las instituciones financieras, incapaces de recuperar el valor de los créditos otorgados, salieron a liquidar activos financieros, agravando el derrumbe de los precios.

El gráfico IX ilustra el riesgo de default de los bancos norteamericanos, que saltó de los 10 puntos básicos en la primera mitad de 2007 a un promedio de 60 p.b. entre agosto de 2007 y agosto de 2008, período que corresponde al primer tramo de la crisis de las hipotecas subprime. Ese promedio saltó a 100 p.b. cuando el gobierno de EE.UU. dejó caer a Lehman Brothers a mediados de septiembre de 2008, y a nada menos que 350 p.b. a mediados de octubre cuando rescató a AIG y sembró en el Congreso graves dudas sobre la coherencia de la política de salvamento bancario.

\section{De la crisis financiera a la crisis económica}

Para la tradición austriaca, las crisis económicas no son únicamente un efecto financiero o de «bolsas», sino que el efecto es real (no neutral) incluso en el largo plazo.

En palabras de Fritz Machlup (1974; p. 504), «la tesis fundamental de la teoría del ciclo económico de Hayek es el factor monetario como causa del ciclo, pero el fenómeno real es lo que la constituye.»

Como hemos visto, durante la fase de expansión, las tasas artificialmente bajas han generado un sesgo hacia inversiones de un plazo mayor al conveniente, dada la tasa natural de mercado. Si esto se mantiene por varios años, los errores de inversión comienzan a acumularse.

Desde 2004, cuando la Reserva Federal contrae la oferta monetaria, muchos proyectos que quizás aún no han sido completados, dejan de ser rentables. Y los recursos que ya se han invertido en ellos no pueden utilizarse en otros proyectos.

Aquel empresario que había proyectado un astillero no puede transformarlo en una fábrica de autos. Prácticamente toda la inversión ha sido perdida. ${ }^{16}$

16 O’Driscoll (2009; p. 178) es aún más claro: «During the high-tech and telecom boom, too many miles of fiber optic cable were laid, and not enough miles of railroad 
En pocas palabras, no sólo se ha invertido mal, sino que se ha retrocedido. Es decir, se ha «destruido» capital en términos económicos.

En este contexto, muchas empresas reducen sus actividades y despiden trabajadores. Así es como la tasa de desempleo en los Estados Unidos ya ha alcanzado el récord de los últimos diez años, y el propio Obama anticipa que alcanzará los dos dígitos.

Esto muestra precisamente el pasaje de B a C en la Curva de Phillips de pendiente positiva. El gráfico XIII nos muestra la recesión de la economía americana y el gráfico XIV nos ilustra sobre el aumento del desempleo.

\section{La respuesta de la Reserva Federal ante la crisis}

En su famoso estudio sobre la Historia Monetaria de los Estados Unidos, Milton Friedman y Anna Schwartz (1963) sostuvieron que la Gran Depresión obedecía a errores de la Reserva Federal. El problema no fue la expansión monetaria y crediticia de los años veinte, decían, sino más bien la contracción secundaria de la oferta monetaria producida entre 1929 y 1933, lo que provocó una gran deflación de precios que destruyó una gran parte del sistema bancario (de los 25.000 bancos que operaban en 1929, sólo quedaron 12.000 en 1933).

¿Qué queremos decir con «contracción secundaria»? Como explicara Roger W. Garrison (2009b) «una espiral descendente de la actividad económica que se realimenta y que provoca que la recesión sea más profunda y/o que dure más de lo que era necesario por la necesitada liquidación de las malas inversiones.»

Friedman y Schwartz, en consecuencia, recomendaban que la Reserva Federal debía evitar una crisis semejante reinflando la oferta monetaria.

¿Tiene esto alguna relación con lo que Bernanke hace hoy? Por supuesto. En noviembre de 2002, en un discurso que Ben

track. That was a manifestation of malinvestment. When the history of the housing bubble is written, we will gain insight into the opportunity cost of malinvestment in housing.» 
Bernanke (2002) ofreció en honor a Milton Friedman, pronunció las siguientes palabras: «Permítanme terminar mi conferencia abusando levemente de mi carácter de representante de la Reserva Federal. Quiero decirles a Milton y a Anna: en lo que respecta a la Gran Depresión, tienen razón, fue culpa nuestra. Lo lamentamos mucho. Pero gracias a ustedes, no volveremos a hacerlo».

Lo cierto es que Ben Bernanke está intentando llevar adelante las políticas que Friedman y Schwartz habrían recomendado seguir ante la Gran Depresión, esto es, expandir la base monetaria para evitar la "contracción secundaria».

Muchos dirán que esta es una política keynesiana, por el rol activo que el gobierno y la Reserva Federal asumen ante la crisis. Sin embargo, hemos de notar que expandir la base monetaria cuando la oferta monetaria se contrae es una operación con cierto consenso en la academia.

¿Incluye este consenso a los austriacos? Por un lado, no. Jesús Huerta de Soto (2009) por ejemplo ha señalado en un reciente artículo titulado Los errores de Ben Bernanke que «en vez de una crisis en $\mathrm{V}$, profunda y rápida (que es lo que el mercado libre propiciaría), la intervención monetaria y gubernamental fuerzan innecesariamente una recesión mucho más prolongada y dolorosa».

Por otro lado, sí. Y es que en la aludida propuesta de Hayek por mantener constante MV afirma que la Reserva Federal, dadas las circunstancias de la gran depresión - similares a las actuales-debe expandir la base monetaria para evitar esta «contracción secundaria». ${ }^{17}$ Hayek proponía (como ideal) que la Reserva Federal permita la necesaria liquidación de mercado mientras la autoridad monetaria evita la contracción secundaria (el pánico) mediante el mantenimiento de un flujo constante de gasto. ${ }^{18}$

\footnotetext{
17 Representa un desafío estudiar las similitudes y diferencias entre Hayek y Röpke respecto del estudio de la contracción secundaria y las políticas que se deben llevar adelante para evitarla. Véase al respecto el comentario que realicé en la Reunión Anual de la Asociación Argentina de Economía Política (AAEP) al trabajo de Marcelo Resico (2009) sobre la teoría del ciclo económico de W. Röpke.

18 Roger W. Garrison (2009b) argumenta que esta política para Hayek sería ideal «en reconocimiento de que la autoridad monetaria puede carecer tanto de la capacidad técnica y de la voluntad política para implementar dicha medida. (Carecería de la
} 
Resulta relevante aclarar que el aumento de la oferta monetaria que proponía Hayek, y hoy defienden Lawrence White (2009) y George Selgin (2008), entre otros, no sería de la magnitud, ni de la calidad, que Bernanke ofrece hoy. Por un lado, hoy la expansión de la oferta monetaria, medida por M2, supera el 15 por ciento, un importe que está bastante por encima de lo que el mercado habría necesitado para evitar la «contracción secundaria». Por otro lado, en lugar de los rescates arbitrarios que la Reserva Federal otorga hoy a la discrecionalidad del gobierno americano, estos autores habrían preferido una expansión de la oferta monetaria a través de operaciones de mercado abierto, esto es, comprando bonos y sin favorecer el «riesgo moral». ${ }^{19}$ De este modo, algunas de las grandes empresas que fueron rescatadas habrían caído y otras habrían sido fusionadas o reestructuradas, dando lugar al ajuste de mercado.

White (2009) sintetiza algunas de las políticas arbitrarias que llevó adelante la Fed desde 2008, y argumenta que esta «nueva Fed», hacia fines de 2008, ya había otorgado un programa de bailout de 1.7 billones de dólares, una suma que duplica el programa que el Congreso le aprobara al presidente Obama cuando llegó a la presidencia. ${ }^{20}$

Desde luego, Hayek favoreció un sistema de banca libre y competencia de monedas en el que se eliminara el curso forzoso,

capacidad técnica porque no tendría forma de conseguir información oportuna sobre los cambios en la velocidad de circulación del dinero; y también carecería de la voluntad política porque sacar dinero de la economía cuando eventualmente la velocidad comience a aumentar es algo políticamente impopular para hacer.)»

${ }^{19}$ Lawrence White (2009, p. 120) señala: «Acting as a lender of last resort is merely an aspect of monetary policy: It means injecting reserves into the commercial banking system to prevent the quantity of money from contracting - when there is an "internal drain" of reserves (bank runs and the hoarding of cash). The "lender" part of the role's name has long been an anachronism. Central banks in sophisticated financial systems discovered many decades ago that they can inject bank reserves without lending, by purchasing securities the central bank supports the money stock while avoiding the danger of favoritism associated with making loans to specific banks on noncompetitive terms (Goodfriend and King 1988). By purchasing Treasury securities it avoids the potential for favoritism in purchasing other securities.»

20 White (2009, p. 121) nos presenta un estudio detallado del balance de la Fed, identificando a las instituciones que sólo a partir de 2008 empezaron a recibir partidas de dinero. 
lo que habría evitado llegar a situaciones como ésta. Pero si asumimos la existencia de un banco central, y ya que estamos inmersos en la crisis, la política de evitar la contracción secundaria parece gozar hoy de cierto consenso.

Los gráficos V, X, XI y XII del anexo II muestran la aludida respuesta de la Reserva Federal ante la crisis. El gráfico V muestra cómo esta institución ha reducido la tasa de interés a corto plazo en más de trescientos puntos básicos, en sólo un año. El gráfico $X$ muestra la evolución de la base monetaria ajustada, que se duplicó entre septiembre de 2008 y enero de 2009. El salto se evidencia también en los gráficos XI y XII, que muestran la evolución de los agregados monetarios M1 y M2.

Estos gráficos sintetizan los nuevos excesos. Es cierto por un lado, como explica Huerta de Soto (2009, p. 233), que «el mercado es muy ágil y rápido a la hora de detectar los errores de inversión y de manera espontánea pone en marcha los procesos necesarios (vía reducción de precios, cambio en su estructura relativa y paralización de los proyectos de inversión no viables) para afrontar la necesaria e ineludible reestructuración cuanto antes y con el mínimo coste.» Sin embargo, los nuevos errores no están exentos de nuevas consecuencias. En pocas palabras, el ajuste puede haberse desarrollado, pero nuevos errores de inversión están surgiendo sobre la base de la nueva baja artificial de la tasa de interés.

En la Curva de Phillips de pendiente positiva tal politica se manifiesta como el pasaje desde $C$ hasta $D$, iniciando lo que será un nuevo ciclo económico, producto de una nueva distorsión de precios relativos y su consecuente mala-inversión. Esto es en definitiva, la crisis en forma de $W$, a la que aludimos más arriba, señalando que la recuperación no será duradera. ${ }^{21}$

21 En este sentido argumenta el presidente del Bundesbank y miembro del BCE, Axel Weber, quien advierte sobre una segunda ola en la crisis financiera. Incluso Alan Greenspan dejó entrever la posibilidad de que «la recuperación económica podría flaquear en 2010», según afirmó en una entrevista para Reuters. "Se observa una recuperación en la construcción de viviendas y en el sector automotriz, pero el proceso no tiene piernas para andar». La venta de coches y el sector inmobiliario, normalmente los motores de la recuperación de la economía, recibieron un impulso mediante planes de estímulo (gasto público), como el programa dinero por chatarra puesto 
En otras palabras, la política monetaria de la Reserva Federal puede ser efectiva en detener la destrucción masiva de empleos en el corto plazo, pero las distorsiones que genera crearán en el futuro un problema mayor.

\section{Los planes de estímulo de Obama y el desempleo}

En materia fiscal, el presidente Obama ha obtenido - incluso antes de asumir la presidencia- la aprobación del Congreso de un plan de estímulo de alrededor de 800 mil millones de dólares cuyo objetivo es crear entre 3 y 4 millones de empleos antes de fines de 2010. El informe titulado «The job impact of the american recovery and reinvestment plan», de sólo 14 páginas, explica que el ciclo económico ha destruido, a diciembre de 2007, 2.6 millones de empleos, alertando que en ausencia del plan podrían perderse alrededor de 3 millones de empleos más.

El gráfico XIV es parte del informe, y muestra la evolución de la tasa de desempleo con y sin el plan de estímulo, suponiendo que un punto porcentual como caída del PBI, representará alrededor de un millón de empleos perdidos. El gráfico nos muestra que, en ausencia del plan, la tasa de desempleo alcanzaría el 9 por ciento, mientras que, en presencia del plan, la tasa de desempleo no llegaría a tocar el 8 por ciento.

Los puntos rojos expuestos sobre el gráfico XIV son un agregado al informe mencionado, mostrando las tasas de desempleo de los meses sucesivos a la implementación del plan. Aquí se observa que la tendencia alcista del desempleo fue bastante mayor a la proyectada, habiendo alcanzado en junio de 2009, una tasa de desempleo de 9.5 por ciento.

Esto no implica que el plan de estímulo haya fracasado en el objetivo de crear puestos de trabajo en el corto plazo. Lo que sí evidencia es que el ciclo económico que surge como consecuencia

en marcha por el Gobierno de EE.UU. Estas ayudas alentaron la demanda de automóviles, pero el ex presidente de la Fed señala que dicho repunte tiene una duración limitada. «La venta de vehículos nuevos podría disminuir una vez que se acabe el programa público de dinero por chatarra», alerta. 
de manipular la tasa de interés a corto plazo, genera un efecto devastador sobre el empleo en el largo plazo, que algunos analistas se equivocan al negar.

La pregunta que surge entonces es: ¿Puede el gobierno mantener estos puestos de trabajo sobre la base de la política fiscal expansiva? La respuesta la observamos en el «rojo fiscal» que el gobierno americano está acumulando. Esta situación se agrava y no parece sostenible.

Greenspan intentó paliar una situación difícil en 2002 a través de la política monetaria, pero nos ha dejado en una situación peor. Hoy Bernanke tiene ante sí una situación similar y, sin embargo, parece repetir los errores cometidos ayer.

\section{$\mathrm{V}$ \\ REFLEXIÓN FINAL}

Anna Schwartz (2008) desarrolló una investigación reciente sobre los ciclos económicos y las burbujas de activos, señalando que en cada episodio histórico el factor causante ha sido la política de dinero fácil, y la demasiado baja tasa de interés.

Uno puede verse tentado a afirmar que lo que falló en esta crisis, como en la gran depresión de los años '30, en el crack de 1987, en la crisis de Japón o en la burbuja de las «dotcom», fue el sistema de la banca central.

Sin embargo, esto puede ser un error. $Y$ es que resulta injusto culpar al titular de la Reserva Federal o de cualquier banco central cuando no hay modo de que éste pueda hacer las cosas bien. En definitiva, como ha reconocido el mismo Greenspan, los responsables de la Fed no tienen forma de saber cuándo una burbuja se está formando. Por más que prestigiosos economistas se esfuercen en hacerlo, no hay modo en que la Fed pueda conocer cuál es la tasa natural de interés. ${ }^{22}$

22 En este sentido argumenta Roger W. Garrison (2009a, p. 198): «Lessons as they relate to the central bank are more problematic. Given the very fact of heavily centralized credit markets, the Federal Reserve is precluded from knowing what interest rate would prevail in a decentralized market. The natural rate of interest is obscured 
La regla de Friedman o de Taylor, entre tantas otras, representan un límite a la expansión de la oferta monetaria, pero si bien son superiores en sus resultados a la discrecionalidad, no son la solución a la inestabilidad y los ciclos económicos.

La tradición de la Escuela Austriaca ha propuesto desde 1912 en adelante, lo que considero puede ser una solución, no a las fluctuaciones económicas - producto de la dinámica en las preferencias, de las expectativas o los descubrimientos tecnológicospero sí a los ciclos económicos - que son siempre consecuencia del intento de manejar científicamente las variables monetarias, como es por ejemplo, la manipulación de la tasa de interés-.

La solución, pienso, está en eliminar la banca central y el curso forzoso, como propusiera Friedrich A. von Hayek (1973) hace ya más de treinta años, dando lugar a una competencia de monedas.

Como ha señalado Gerald O'Driscoll (2009; p. 174) «una combinación de reglas y discrecionalidad ha jugado un importante rol en la actual crisis.» El problema entones, ¿es la teoría o la política? En otra oportunidad, he manifestado que debemos «ampliar del debate» (Ravier, 2008).

Y para terminar, nos remitimos al artículo del comienzo de Leijonhufvud (2008a), quien sostiene que los eventos actuales deberían forzarnos a re-examinar la doctrina reciente de la política monetaria y en general la teoría macroeconómica moderna. En particular, pone el acento en la tasa de interés real, la teoría de la equivalencia ricardiana, la teoría financiera moderna, la teoría del agente representativo y las expectativas racionales.

Pocos dudan que la doctrina requiera ser revisada. Lo que aquí planteamos no es que Hayek y la tradición austriaca representan esa doctrina. Simplemente que en esta tradición se pueden encontrar algunas respuestas.

by the Federal Reserve's apparatus for managing interest rates - all the more so when yields on securities only dimly reflect the underlying risks. In the future, postcrisis period, the FOMC will be ill-advised to resume some learning-by-doing strategy. Interest-rate targeting should be ruled out on the basis of the cumulative evidence - namely, the Federal Reserve's dramatically demonstrated inability to target a Fed funds rate that is consistent with sustainable growth.» 


\section{REFERENCIAS BIBLIOGRÁFICAS}

BERNANKe, B. (2009): Four Questions about the Financial Crisis, Speech at the Morehouse College, Atlanta, Georgia.

- (2007): Global Imbalances: Recent Developments and Prospects, Speech at the Bundesbank Lecture, Berlin, Germany.

- (2006): Reflections on the Yield Curve and Monetary Policy, Speech before the Economic Club of New York, New York.

- (2005): The Global Saving Glut and the U.S. Current Account Deficit, Remarks by Governor Ben Bernanke en la Sandridge Lecture, Virginia Association of Economics, Richmond, Virginia.

- (2002): On Milton Friedman's ninetieth birthday, Remarks by Governor Ben Bernanke, University of Chicago, Chicago, Illinois, November 8, 2002.

CACHANOSKY, J.C. (2002): «Crisis económicas: causas y consecuencias», Libertas, N.o 36, mayo de 2002.

CACHANOSKY, N. (2010): «¿Por qué el saving glut no puede explicar al crisis internacional?», GPS Económico, Año 1, N.1, Buenos Aires, enero de 2010.

CRESPO, R.F. (1998): «Subjetivistas radicales y hermenéutica en la escuela austriaca de economía», Sapienta, Volumen LIII, Fascículo 204, pp. 419-429.

DowD, K. (2009): «Moral Hazard and the Financial Crisis», Cato Journal, Vol. 29, N. 1 (Winter 2009), pp. 141-166.

FisHER, I. (1933): «The Debt-Deflation Theory of Great Depressions», Econometrica, 1, October, pp. 337-357.

- (1963) [1922]: The Purchasing Power of Money, Reprint of the second revised edition, New York: Augustus M. Kelley, 1963.

Friedman, M. (2000): «El auge de los 90s se desinfló», Cato Institute, 1 de febrero de 2000.

- (1976): Nobel Memorial Lecture: Inflation and Unemployment, Nobel Foundation, December 13, 1976. Existe una versión en español bajo el título «Inflación y desempleo: la nueva dimensión de la política», en «La Economía Monetarista», editado por Editorial Gedisa S.A., Barcelona, España, noviembre 1992.

- (1975): «Unemployment versus inflation», IEA, Lecture N.. 2, Occasional paper N.․ 44, Londres. Existe una versión 
en español bajo el título «¿Desempleo versus inflación? Evaluación de la curva Phillips», en «La Economía Monetarista», editado por Editorial Gedisa S.A., Barcelona, España, noviembre 1992.

Friedman, M. y SchwartZ, A.J. (1963): A monetary history of the United States, 1867-1960, Princeton: Princeton University Press (for the NBER): 1963.

GARRISON, R.W. (2009a): «Interest-rate targeting during the great moderation: a reappraisal», Cato Journal, Vol. 29, N.․ 1 (Winter 2009), pp. 187-200.

- (2009b): «Mainstream macro in an austrian nutshell», The Freeman: Ideas on Liberty, Volume 59, Issue 4, may 2009.

- (2006): «The Greenspan Fed in Perspective», The Freeman: Ideas on Liberty, FEE, june 2006.

- (2001): Time and Money, The Macroeconomics of Capital Structure, Routledge.

GreENSPAN, A. (2008a): La era de las turbulencias, Ediciones B, Barcelona.

- (2008b): «The Fed Didn't Cause the Housing Bubble», The Wall Street Journal, 11 de marzo de 2009.

- (2008c): «Alan Greenspan: A Response to my Critics», Financial Times Economist's Forum, 6 de abril.

- (2007): «The Roots of the Mortgage Crisis», The Wall Street Journal, 12 de diciembre.

- (2005): Federal Reserve Board's semiannual Monetary Policy Report to the Congress, Before the Committee on Banking, Housing, and Urban Affairs, U.S. Senate, 16 de Febrero.

HAYEK, F.A. von (1979): ¿Inflación o Pleno Empleo?, México: Editorial Diana, edición autorizada por Unión Editorial.

- (1981) [1978], Nuevos estudios en filosofía, política, economía e historia de las ideas, Editorial Universitaria de Buenos Aires, EUDEBA. Traducción de «New studies in Philosphy, Politics, Economics and the History of Ideas» (1978) por María Isabel Alves y Denise Rivero.

- (1973): La desnacionalización del dinero, Instituto de Economía de Mercado, Madrid, Unión Editorial.

- (1933) [1929], Monetary theory and the trade cycle, Clifton, New Jersey: Augustus M. Kelley reprint 1966. Original German 
1929. Translated from the German by N. Kaldor and H.M. Croome.

- (1996) [1931], Prices and Production, Routledge and Sons, Londres, 1931.

Hoyos, D.A. (2007): «El rol de las expectativas y las instituciones en los modelos económicos austriacos», La Escuela Austriaca en el Siglo XXI, Fundación Friedrich A. von Hayek y Fundación Bases, Buenos Aires, mayo de 2007, pp. 137-149. Compiladores: Adrián O. Ravier y Federico Fernández.

Huerta de Soto, J. (2009): «El error fatal de Ben Bernanke», Procesos de Mercado: Revista Europea de Economía Politica, Vol. VI, N.․․ 1, Primavera 2009, pp. 233-236.

- (2008): «Financial Crisis and Recession», Mises Daily, 10 de junio.

- (2001) [1998], Dinero, crédito bancario y ciclos económicos, Unión Editorial, Madrid.

HumphreY, TH. M. (1984): «On Nonneutral Relative Price Effects in Monetarist Thought: Some Austrian Misconceptions», Federal Reserve Bank of Richmond, May/June 1984, pp. 13-19.

Krause, M.E., Ravier, A.O., y Zanotti G. (2007): Elementos de Economía Política, Editorial LA LEY, Buenos Aires, agosto de 2007.

Krugman, P. (2009): «A dark age of macroeconomics», Wall Street Journal, Opinión, 27 de enero de 2009.

- (2002): «Dubya's Double Dip?», The New York Times, Opinión, 2 de agosto de 2002.

LaChMANN, L. (1955): Capital and its structure, Sheed Andrews and McMeel Inc. Septiembre de 1955.

Leijonhufvud, A. (2008a): «Keynes and the crisis», Policy Insight N.. 23, Centre for Economic Policy Research, May 2008.

- (2008b): «Monetary and Financial Stability», Policy Insight N. ․14, Centre for Economic Policy Research, October 2007.

- (2000): «Mr. Keynes y los Modernos», Desarrollo Económico, Vol. 39, N.o 156, enero-marzo de 2000, pp. 499-518.

- (1968): On keynesian economics and the economics of Keynes: A study in monetary theory, New York, Oxford University Press.

LuCAS, R. (1973): «Some International Evidence on Output-Inflation Tradeoffs», The American Economic Review, Vol. 63, N. 3. (Jun, 1973), pp. 326-334. 
Machlup, F. (1974): «Friedrich von Hayek's contributions to economics», Swedish Journal of Economics, 76, pp. 498-531.

Meltzer, A.H. (2009): «Reflections of the financial crisis», Cato Journal, Vol. 29, N. 1 (Winter 2009), pp. 25-30.

Mises, L. von (1997) [1912]: La Teoría del Dinero y del Crédito, Unión Editorial, Madrid, España.

Muth, J. (1961): «Rational expectations and the theory of prices movements», Econometrica 29, p. 24.

Niskanen, W.A. (2002): «On the death of the Phillips Curve», Cato Journal, Vol. 22, N. 2 (Fall 2002), pp. 193-198.

O'Driscoll, G.P. (2009): «Money and the present crisis», Cato Journal, Vol. 29, N. 1 (Winter 2009), pp. 167-186.

O'Driscoll, G.P. y Rizzo M.J. (1996, [1985]): The Economics of Time and Ignorance, 1..$^{\mathrm{a}}$ edición, Basil Blackwell, Oxford 1985, 2. ${ }^{\mathrm{a}}$ edición, Routledge, Londres, 1996, p. 222. Edición española de Unión Editorial, Madrid 2009.

PhilLIPS, A.W.H. (1958): «The relation between unemployment and the rate of change of money wage rates in the United Kingdom, 1861-1957», Economica, Vol. 25. Versión en español en Mueller M.G.: «Lecturas en macroeconomía». Ed. CECSA (1974).

RAllo, J.R. (2009): «No fue el exceso de ahorro», Cato Institute, 18 de mayo de 2009. Disponible en El Cato.org

Ravier, A.O. (2010a): En busca del pleno empleo. Estudios de macroeconomía austriaca y economía comparada, Unión Editorial, Madrid.

- (2010b): «La no neutralidad del dinero en el largo plazo. Un debate entre Chicago \& Viena», Cuadernos de Economía, N.o 52, Universidad Nacional de Colombia, Bogotá.

- (2009): Comentario al trabajo de Marcelo Resico: «La teoría del ciclo económico de W. Röpke», en la reunión anual de la Asociación Argentina de Economía Política (AAEP), Mendoza, noviembre de 2009.

- (2008a): «Regla monetaria versus discrecionalidad: una ampliación del debate», Revista de Instituciones, Ideas y Mercados (RIIM), N. ํ 48, ESEADE, Buenos Aires, pp. 113-148.

- (2008b): «Dos tradiciones y un debate en torno a la neutralidad del dinero en el largo plazo», Revista de Análisis 
Institucional N.․ 2, Fundación Friedrich A. von Hayek, marzo de 2008, pp. 213-288.

- (2002): «Estados Unidos en una nueva gran depresión», Fundación Atlas para una Sociedad Libre (hoy Atlas 1853), Buenos Aires, noviembre de 2002.

ReIsman, G. (2009): «Credit expansión, crisis, and the myth of the saving glut», Mises Daily, Ludwig von Mises Institute, 7 de julio de 2009.

Resico, M.F. (2008): La estructura de una economía humana: reflexiones en cuanto a la actualidad del pensamiento de W. Röpke, Educa, 1ra edición, Buenos Aires.

Restribo, N. (2002): «Los números de un derrumbe espectacular en Wall Street», Clarín, domingo 28 de julio de 2002.

RoBerTs, R. (2008): «How Government Stoked the Mania, Housing prices would never have risen so high without multiple Washington mistakes», Wall Street Journal, October $3^{\text {th }}, 2008$.

Rosende, F. y JÜrgENSEN, K. (1993): «Hayek y el ciclo económico: una revisión a la luz de la macroeconomía moderna», Documento de trabajo, N. 154, IE de la Universidad Católica de Chile, Santiago de Chile, marzo de 1993.

Salerno, J. (2002): «An Austrian Taxonomy of Deflation with Applications to the U.S.», Quarterly Journal of Austrian Economics 6 (4): 81-109.

SAMUELSON, R. y SOLOW, R. (1960): «The problem of achieving and maintaining a stable price level». Versión en español en Mueller M.G.: «Lecturas en Macroeconomía». Ed. CECSA (1974).

SCHENONE, O. y RAVIER, A.O. (2008): Vienna \& Chicago: friends or foes? A tale of two schools of free-market economics. Mark Skousen, History of Economics Review, 46, The Australian National University (ANU), Summer 2007, pp. 190-194.

SCHWARTZ, A.J. (2009): «Origins of the financial market crisis of 2008», Cato Journal, Vol. 29, ․o 1 (Winter 2009), pp. 19-23.

- (2008): «Bernanke Is Fighting the Last War», The Wall Street Journal, October 18, 2008.

Selgin, G.A. (2008). Good Money, University of Chicago Press and The Independent Institute.

- (1988): The Theory of Free Banking. New Jersey: Rowman \& Littlefield. 
SHackLe, G.L.S. (1990) [1949], Expectations in economics, Hyperion Press, Inc. Westport, Connecticut.

TAYLOR, J.B. (2009a): «The Need to Return to a Monetary Framework», presentado en la NABE Panel en la AEA Meetings, Slides, Jan 3, 2009.

- (2009b): Monetary Policy and the Recent Extraordinary Measures Taken by the Federal Reserve, Testimony before House Financial Services Committee, Feb 26, 2009.

- (2008): «The Financial Crisis and the Policy Responses: An Empirical Analysis of What Went Wrong», Written version of keynote at Bank of Canada, November 2008

- (2007): Housing and Monetary Policy, presentado en el Policy Panel at the Symposium on Housing, Housing Finance, and Monetary Policy sponsored by the Federal Reserve Bank of Kansas City in Jackson Hole, Wyoming.

- (2005): «Lessons Learned from the Greenspan Era», Federal Reserve Bank of Kansas City Conference, Wyoming, August 25-27, 2005.

- (1993): «Discretion versus policy rules in practice», Carnegie-Rochester Conference Series on Public Policy, 39: 195-214.

TAYLOR, J.B. y SMITH, J.M. (2007): «The Long and the Short End of the Term Structure of Policy Rules», NBER, Working Paper 13635.

White, L.H. (2009): «Federal Reserve Policy and the Housing Bubble», Cato Journal, Vol. 29, N. 1 (Winter 2009), pp. 115-125.

- (2008): «How Did We Get into This Financial Mess?», Briefing Papers, N. ${ }^{\circ}$ 110, Cato Institute, November, $18^{\text {th }}, 2008$.

- (1993): «La Banca Central: Una recapitulación», Libertas, N.. 19, ESEADE, octubre de 1993, pp. 3-31.

- (1989): Competition and Currency. Essays on Free Banking and Money, New York and London: New York University Press.

Wolf, M. (2007): «Villains and Victims of Global Capital Flows», Financial Times, 12 de junio.

YEAGER, L.B. (2009): «The contagious crisis», Liberty, Vol. 23, ‥ 7, Liberty Fund, august 2009. 


\section{ANEXO I:}

EL DEBATE DE LA CURVA DE PHILLIPS.

GRÁFICOS I AL IV

GRÁFICO I

\section{LA CURVA DE PHILLIPS KEYNESIANA}

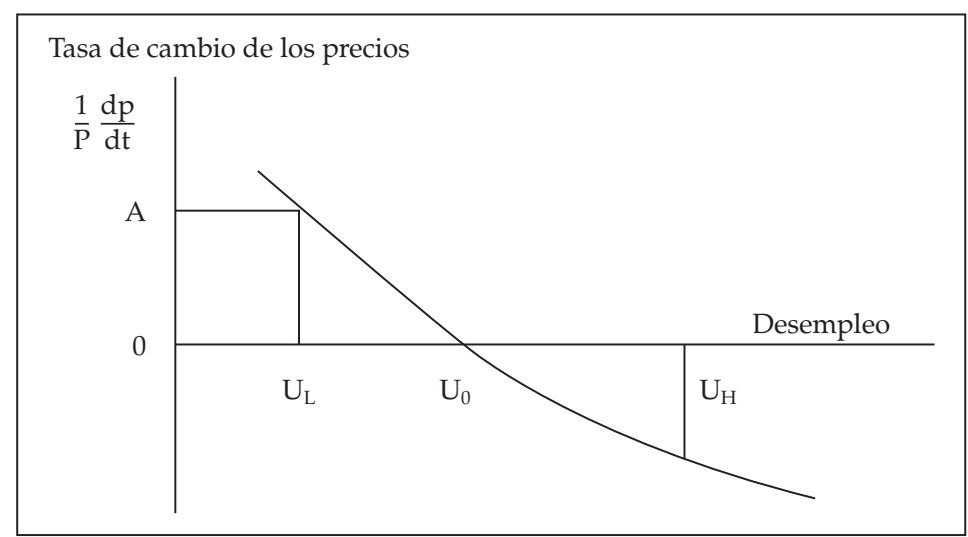

GRÁFICO II

LA CURVA DE PHILLIPS AJUSTADA POR EXPECTATIVAS

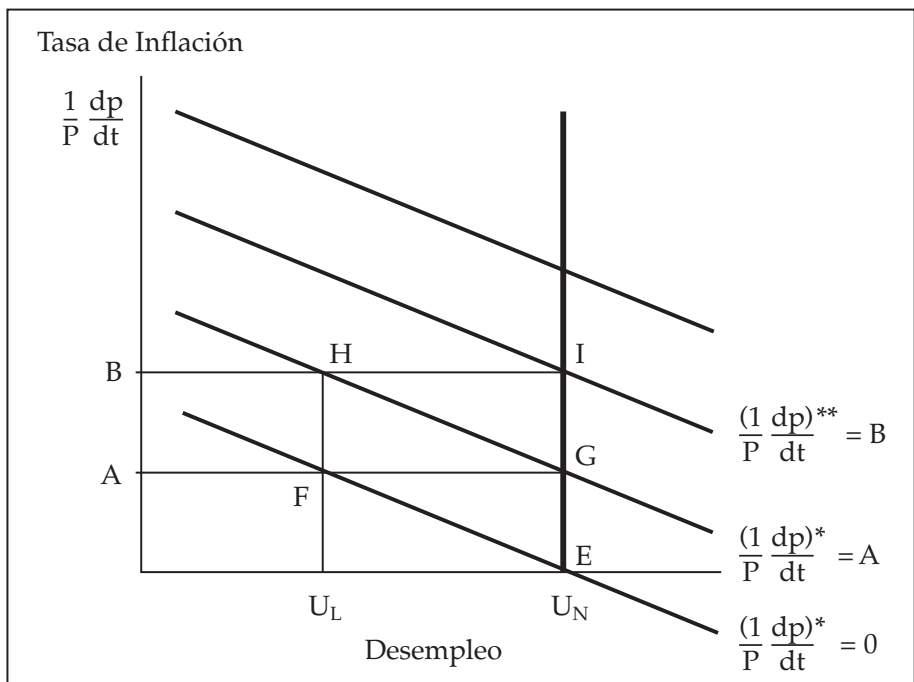


GRÁFICO III

LA CURVA DE PHILLIPS Y LAS EXPECTATIVAS RACIONALES

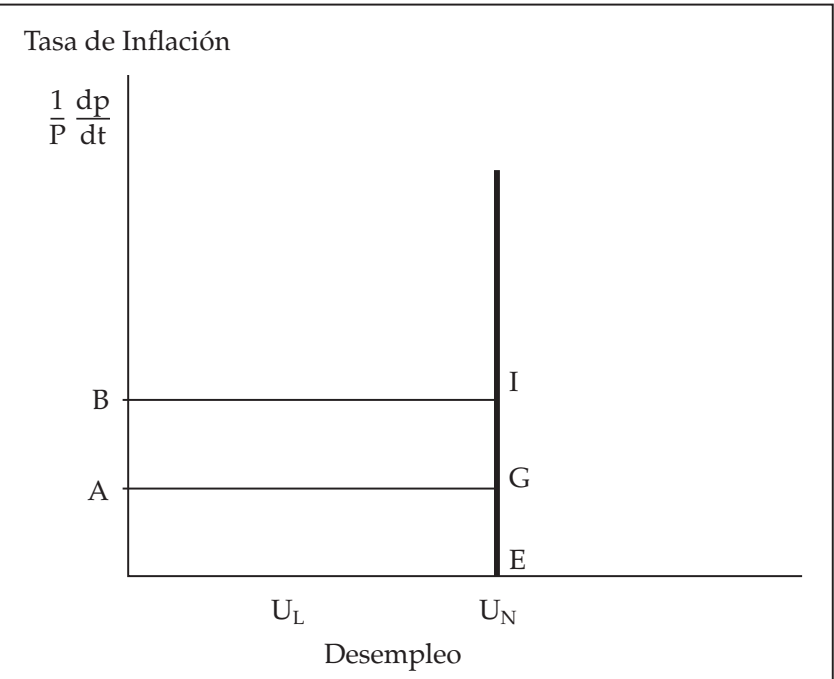

GRÁFICO IV

LA CURVA DE PHILLIPS AUSTRIACA

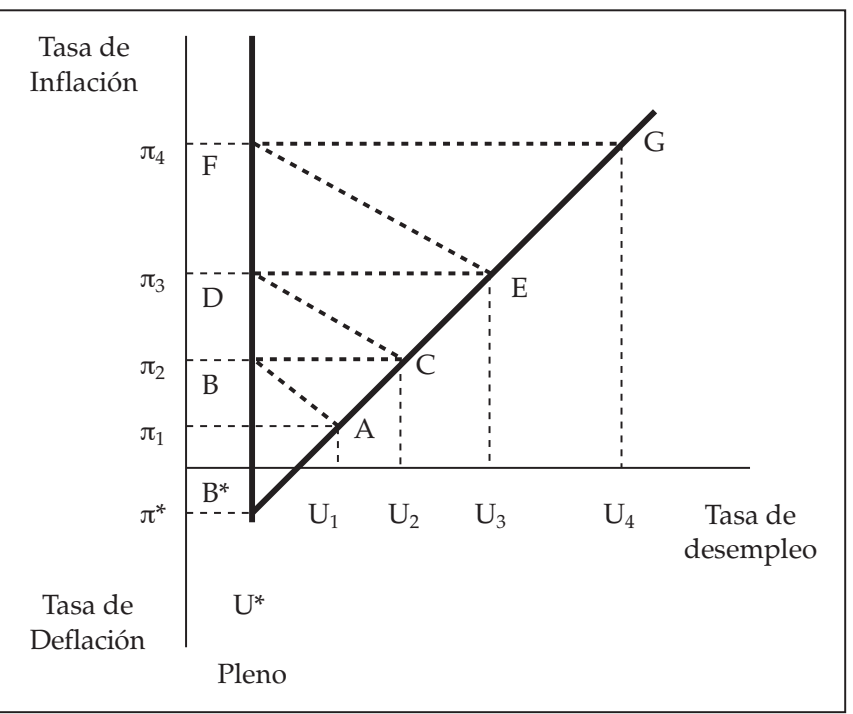


ANEXO II:

LA CRISIS DE 2008.

CAUSAS Y RESPUESTAS

GrÁFICO V

EVOLUCIÓN DE TASA DE INTERÉS A CORTO PLAZO

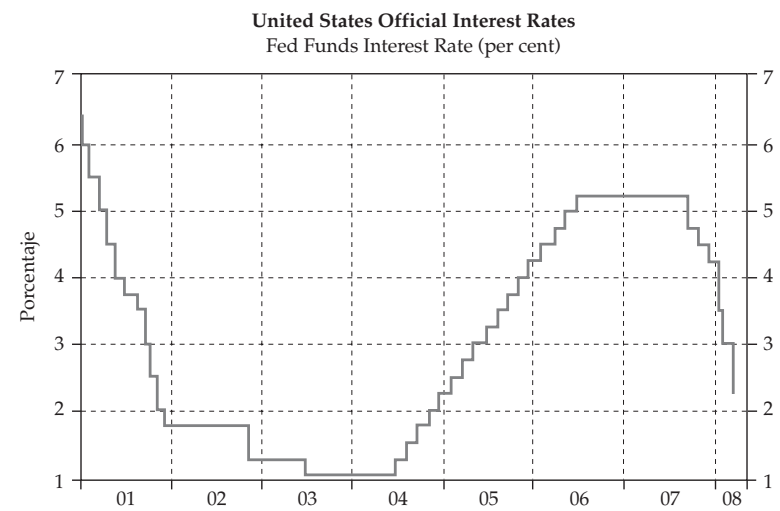

Fuente: Reuters EcoWin.

GrÁfico VI

EVOLUCIÓN DE TASA DE INTERÉS A LARGO PLAZO. MÍNIMOS HISTÓRICOS PARA HIPOTECAS EN 2003-2005

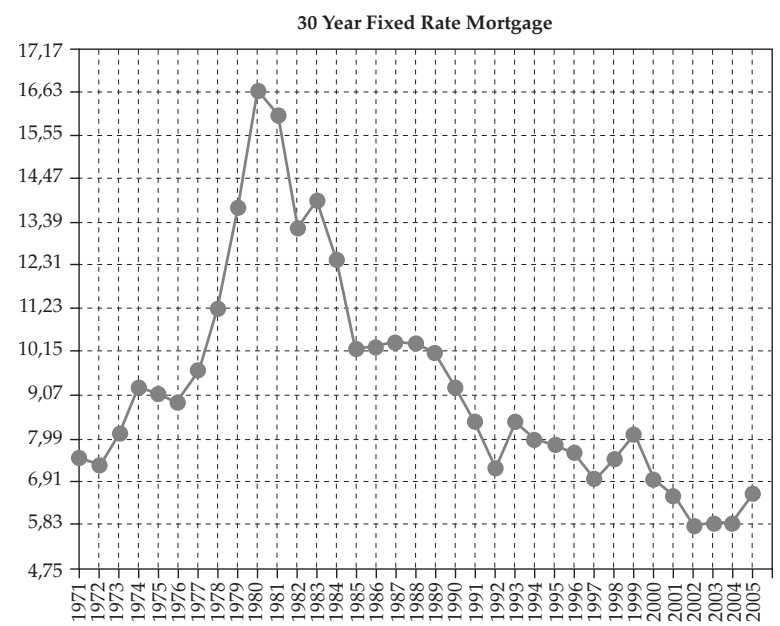


GRÁFICO VII

REGLA DE TAYLOR Y EXCESOS DE LA FED

Loose fitting

Federal funds rate, actual and counterfactual, $\%$

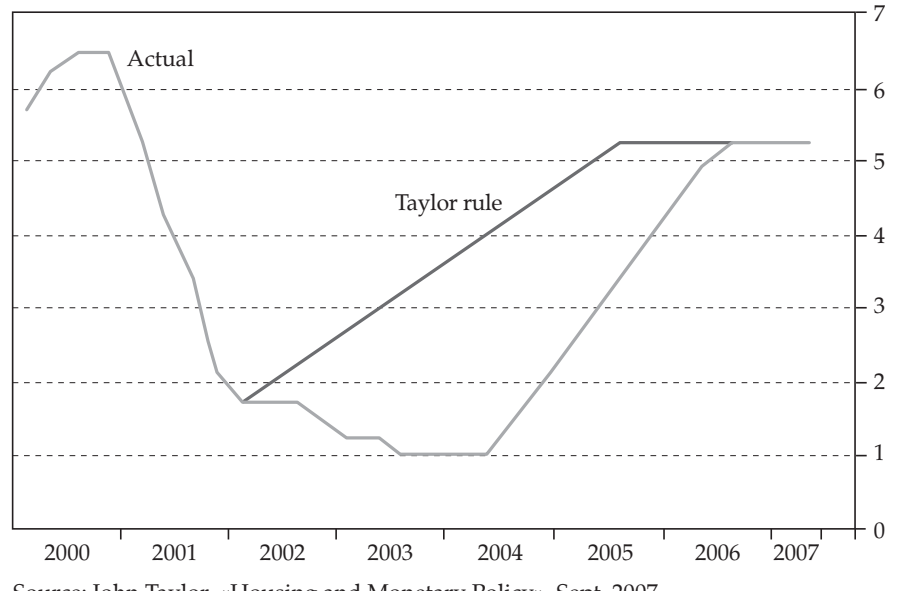

Source: John Taylor, «Housing and Monetary Policy», Sept. 2007.

Fuente: The Economist, 18 de octubre de 2007.

GRÁFICO VIII

CONSECUENCIA DE REDUCIR LOS TIPOS DE INTERÉS. EL BOOM-BUST DE LOS PERMISOS DE CONSTRUCCIÓN VS. EL CONTRAFÁCTICO DE JOHN TAYLOR

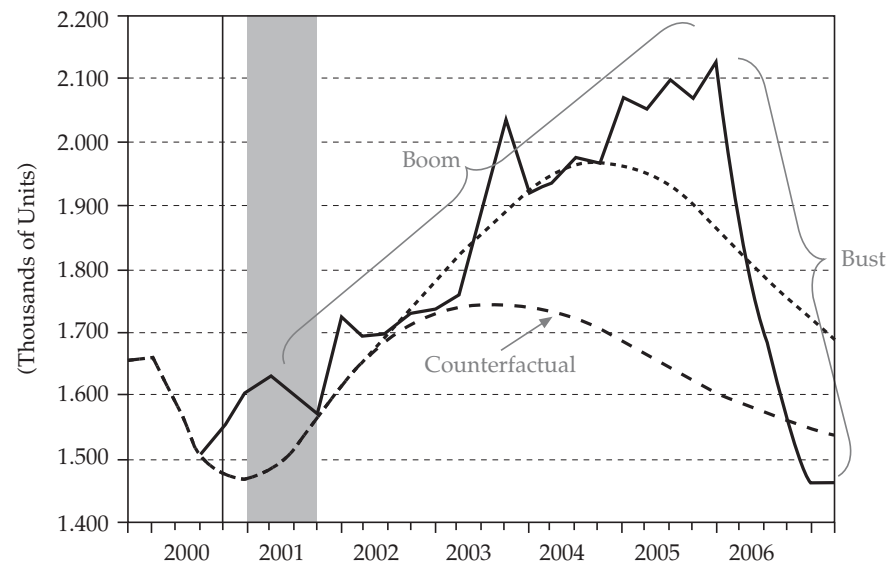


GRÁFICO IX
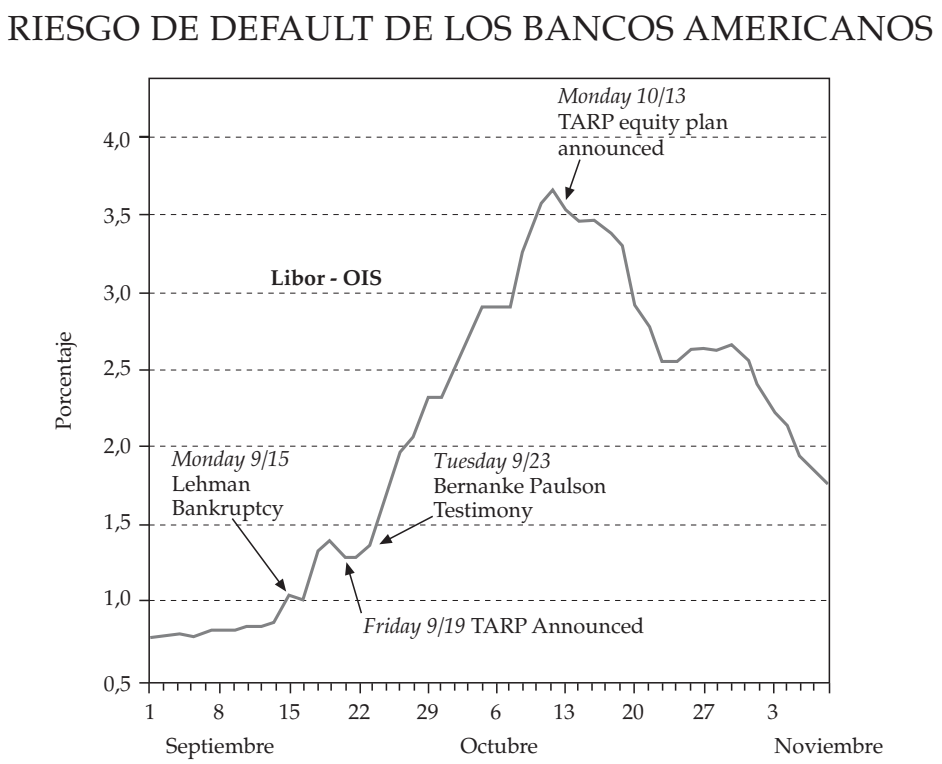

GRÁFICO X

LA SOLUCIÓN DE LA FED A LA CRISIS.

DUPLICAR LA BASE MONETARIA

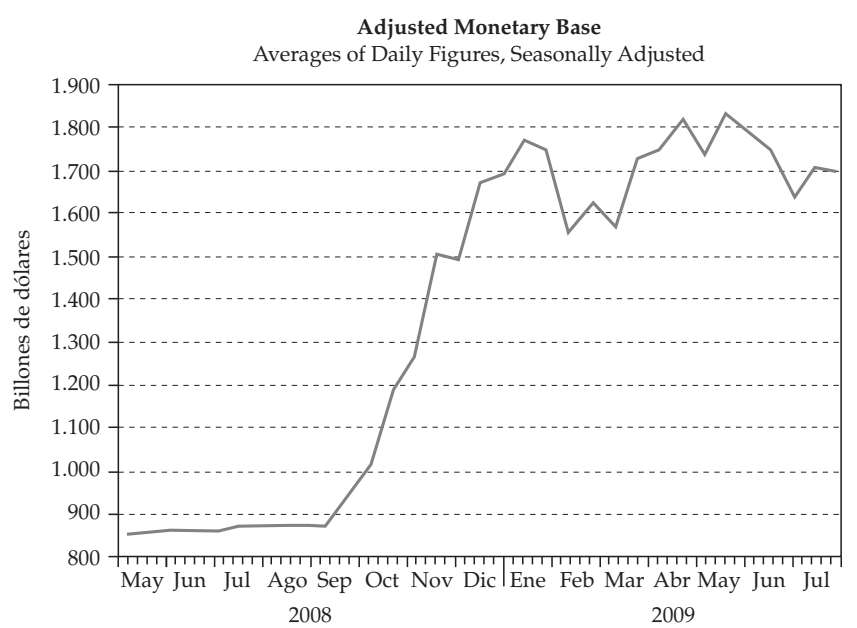

Fuente: St. Louis Federal Reserve. 
GrÁFICO XI

AGREGADO MONETARIO M1 PROYECTADO

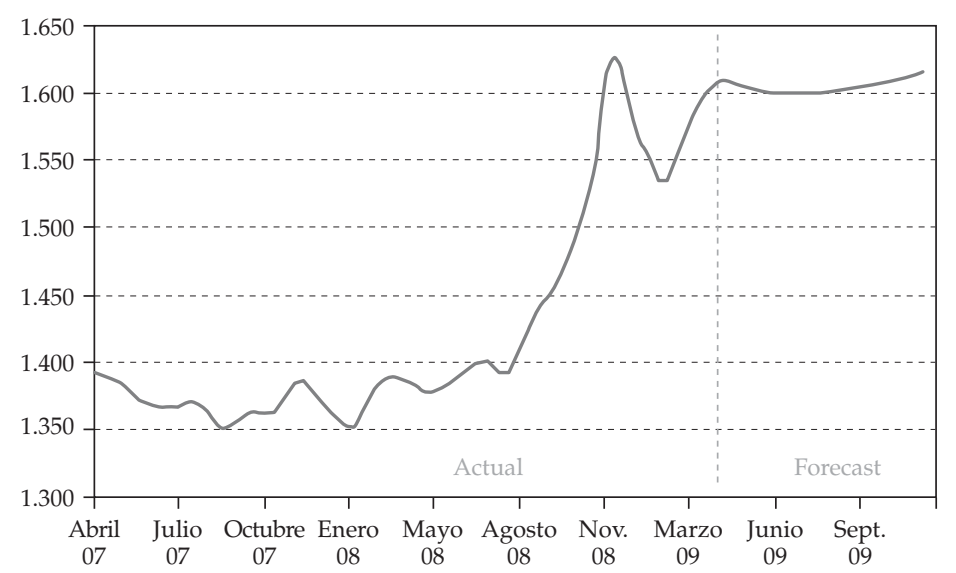

Fuente: Federal Reserve. Billions US Dollars. Not Seasonally Adjusted.

GRÁFICO XII

AGREGADO MONETARIO M2

M2

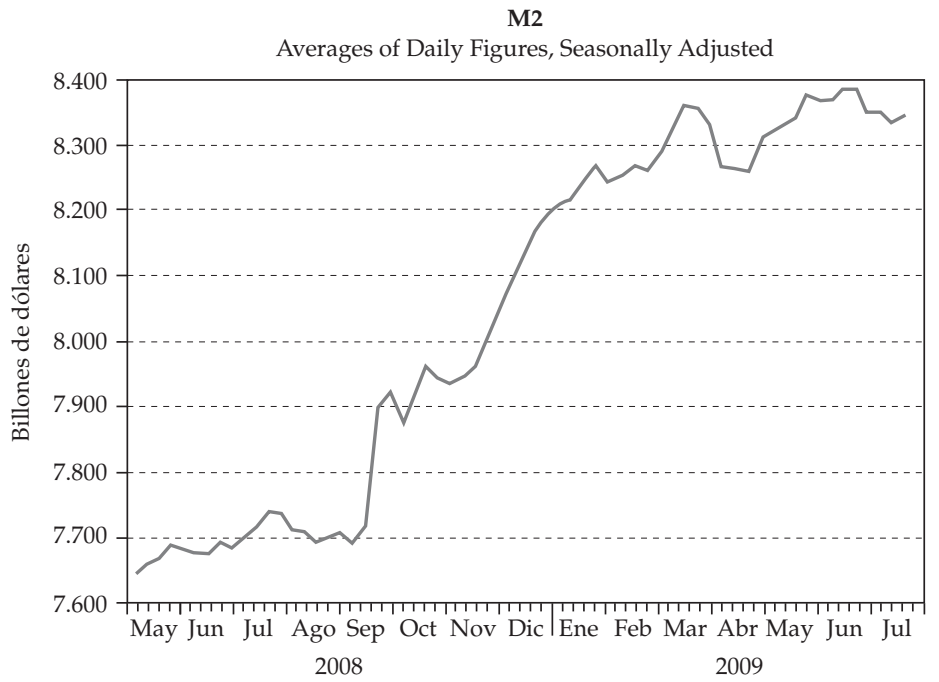

Fuente: St. Louis Federal Reserve. Billions US Dollars. Not Seasonally Adjusted. 
GRÁFICO XIII

EVOLUCIÓN DEL PBI REAL

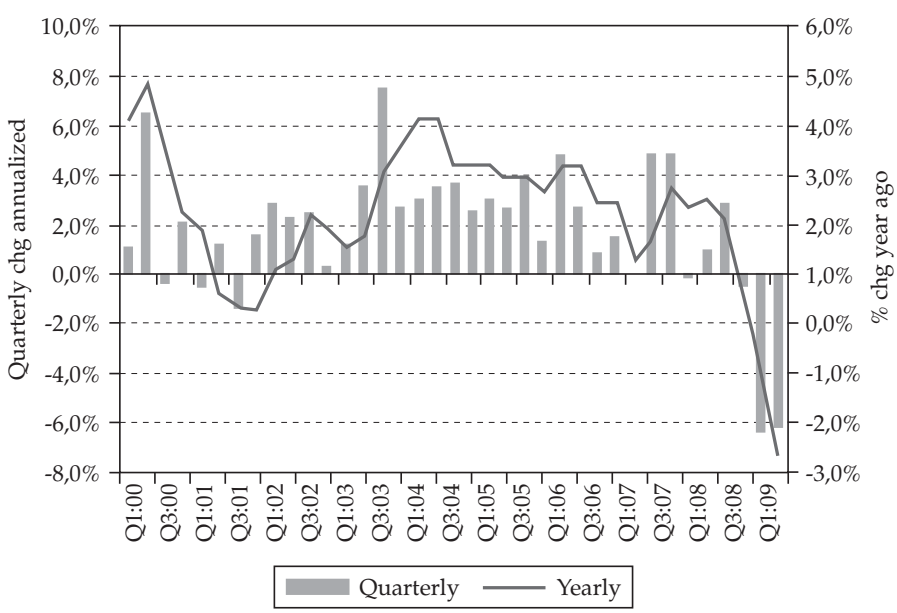

Fuente: The job impact of the american recovery and reinvestment plan, January 2009.

\section{GRÁFICO XIV}

EL DESEMPLEO Y LA EFICACIA DEL PLAN OBAMA

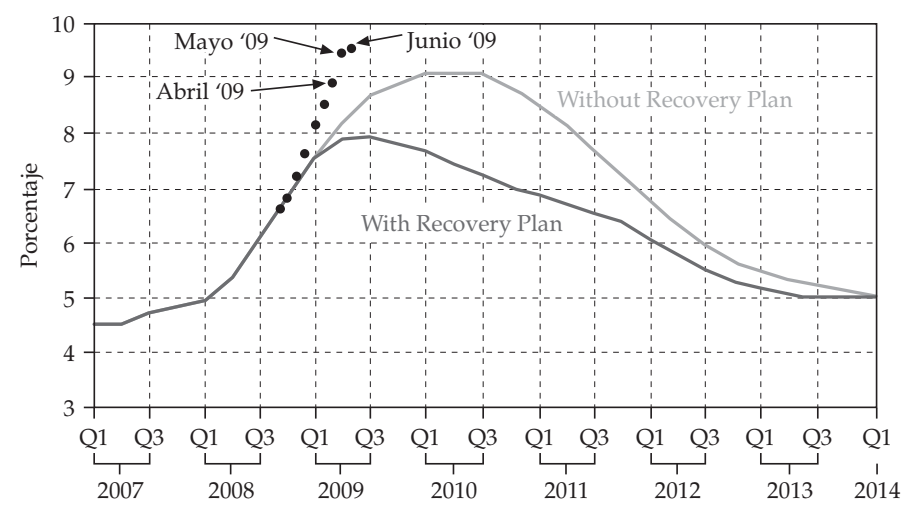

—@ Marcon dots are actual unemployment data
Everything in blue was created by Obama's economic team
http:/ /innocentbystanders.net

Fuente: The job impact of the american recovery and reinvestment plan, January 2009. 